\title{
LIBERTAD PROFESIONAL DEL MÉDICO EN EL NUEVO CONTEXTO DE LA RELACIÓN CLÍNICA: SU DELIMITACIÓN DESDE UNA PERSPECTIVA CONSTITUCIONAL
}

\author{
Professional freedom of the physician in the new \\ context of the clinical relationship: Its delimitation \\ from a constitutional perspective
}

\author{
FEDERICO DE MONTALVO JÄÄSKELÄINEN \\ Universidad Pontificia Comillas ICAI-ICADE \\ fmontalvo@icade.comillas.edu
}

Cómo citar/Citation

Montalvo Jääskeläinen, F. de (2017).

Libertad profesional del médico en el nuevo contexto de la relación clínica:

su delimitación desde una perspectiva constitucional.

Derecho Privado y Constitución, 31, 11-51.

doi: https://doi.org/10.18042/cepc/dpc.31.01

(Recepción: 13/1/2017. Aceptación tras revisión: 19/9/2017. Publicación: 27/11/2017)

Resumen

La relación médico-paciente se ha visto sujeta, en las últimas décadas, a unos cambios muy trascendentales. Así, esta relación, que era puramente bilateral, se ha transformado en una relación trilateral en la que, junto al paciente y al profesional, interviene la organización. No estamos ya ante una relación privada entre dos sujetos, sino ante una relación mucho más compleja en la que el papel de la organización determina en gran medida la toma de decisión, sobre todo, cuando se trata de la sanidad como un servicio público. Igualmente, la relación se ha visto sustancialmente alterada por el principio de autonomía de voluntad del paciente, de manera que, por encima 
de la libertad de decisión del médico, se sitúa tal autonomía. Tales cambios permiten preguntarse si la libertad de actuación que se reconoce tradicionalmente a los profesionales y, en nuestro caso, al médico se mantiene vigente, es decir, si sigue teniendo ya sentido mantener que goza de tal libertad en un marco tan diferente a aquel en el que esta se consagra. Nuestro debate se centra en analizar los principales cambios que han alterado la relación médico-paciente y qué significado tiene hablar, en la actualidad, de libertad de actuación médica cuando la decisión del profesional viene determinada tanto por la decisión del poder público prestador del servicio como por el derecho a autorizar el tratamiento del que es titular el paciente.

\title{
Palabras clave
}

Libertad profesional; Estado social; servicio público sanitario; consentimiento informado; principio de no maleficencia; objeción de conciencia; derecho a la salud.

\begin{abstract}
The physician-patient relationship has been subject in recent decades to very important changes. From a purely bilateral relationship, currently we find a trilateral relationship, which together with the patient, the profesional and the organization involved. We are no longer at a private relationship between two individuals. It is a more complex relationship in which the role of the organization determines decision making process, especially when health assistance is a public service. Similarly, the relationship has been substantially altered by the principle of patient autonomy, so that the physician decision lies on that autonomy. Such changes raise the question whether freedom of medical decision remains in force, ie, if physicians are still enjoying such freedom in such a different context to that in which it arises. Our debate, therefore, will focus on analyzing the major changes that have altered the physician-patient relationship and what does it mean to speak today of freedom of medical decision, when it is determined both by the decision of public service provider and by the right to authorize treatment which is owned by the patient.
\end{abstract}

\section{Keywords}

Professional freedom; Welfare State; public healthcare system; informed consent; principle of non-maleficence; conscientious objection; right to health. 


\section{SUMARIO}

I. INTRODUCCIÓN. II. LA DOBLE DIMENSIÓN DE LA LIBERTAD DE ACTUACIÓN MÉDICA. III. LA REGULACIÓN DE LA LIBERTAD DE ACTUACIÓN MÉDICA. IV. LA AUTONOMÍA DEL PACIENTE COMO LÍMITE A LA AUTONOMÍA DEL MÉDICO. V. EL SISTEMA PÚBLICO DE SALUD COMO LÍMITE A LA AUTONOMÍA DEL MÉDICO. VI. LA OBJECIÓN DE CONCIENCIA COMO UN PRESUPUESTO DE GARANTÍA DE LA LIBERTAD MÉDICA. VII. CONCLUSIONES. BIBLIOGRAFIA.

\section{INTRODUCCIÓN}

La libertad de actuación médica constituye una de las principales garantías del médico en el ejercicio de su profesión. No se trata de una figura atribuible en exclusiva a las profesiones sanitarias o, específicamente, a los galenos, sino que se incardina dentro de la propia libertad de actuación que, con carácter general, se reconoce a todos los profesionales, especialmente a los que son incluidos bajo la expresión tradicional de profesionales liberales (véase, entre otros, abogados, arquitectos o, singularmente, los docentes a través de la constitucionalmente consagrada libertad de cátedra).

El fundamento de esta libertad de actuación profesional no es otro que garantizar la prestación de un mejor servicio al cliente, que se presume que se ha de lograr con una mayor facilidad por quien es libre para decidir de acuerdo con su propio criterio técnico-científico, exento de toda presión externa (De los Reyes, 2001: 343). Tal libertad ha sido definida en el ámbito de la asistencia sanitaria como la «aptitud del médico para elegir aquel tratamiento que, conforme a su leal saber y entender, considera más idóneo y eficaz para el paciente» (Villar Rojas, 1997: 109). Como tal libertad, tradicionalmente, el médico no podía ser objeto de restricciones de clase alguna: ni reglamentarias cuando ejercía la medicina para una administración pública, ni contractuales cuando ejercía la medicina privada. No obstante, se establecían tres límites en el ejercicio de esta libertad: 1) la necesidad, idoneidad y eficacia del tratamiento para enfrentar la enfermedad, 2) el respeto a las prohibiciones legales — uso de sustancias prohibidas o intervenidas - y 3) la sujeción del tratamiento a las normas ordenadas por la lex artis y acomodo al estado de la ciencia. Por estos límites, se ha sostenido que, en lugar de libertad de diagnóstico, tratamiento y prescripción, 
debe hablarse de una obligación de diagnóstico, tratamiento y prescripción; es decir, nos situamos en la categoría de los derechos-deberes. El médico ha estado siempre obligado deontológica y jurídicamente a seguir la terapéutica que sea necesaria, idónea y preferente para el caso en cuestión. De no hacerlo, infringirá su deber de cuidado e incurrirá en responsabilidad deontológica y profesional (Villar Rojas, 1997: 109).

La libertad de actuación profesional es consustancial al propio concepto de profesión, y se puede afirmar que constituye un atributo que la define. Así, la Exposición de Motivos de la Ley 44/2003, de 21 de noviembre, de Ordenación de las Profesiones Sanitarias, afirma que «El concepto de profesión es un concepto elusivo que ha sido desarrollado desde la sociología en función de una serie de atributos como formación superior, autonomía y capacidad auto-organizativa, código deontológico y espíritu de servicio, que se dan en mayor o menor medida en los diferentes grupos ocupacionales que se reconocen como profesiones».

Se trata, por tanto, no solo de una garantía consustancial al ejercicio de la profesión, sino de un elemento que integra el propio concepto de profesional. Tal autonomía impide que terceros ajenos a la relación profesional influyan o intervengan en la toma de decisión por parte del profesional que ha de responder al mejor interés del cliente. Como tal libertad encuentra como principal destinatario el propio Estado que no solo debe promover las condiciones necesarias para que dicha libertad quede garantizada, sino que, además, debe abstenerse de interferir en el ámbito de decisión del profesional.

Normativamente, dicha libertad se consagra en el art. 35 de la Constitución española (CE) que proclama la libertad de elección de profesión, debiendo admitirse que bajo tal derecho se protege no solo el propio hecho de la elección de la profesión, sino la posibilidad de ejercerla en libertad, o lo que viene a ser lo mismo, sin más límites que los previstos por el ordenamiento jurídico. La libertad de elección garantiza tanto el acceder a un estatus como el mantenerse en este ${ }^{1}$.

Junto a lo dispuesto en el art. 35, el siguiente art. 36 señala que la ley regulará las peculiaridades propias del régimen jurídico del ejercicio de las profesiones tituladas; y ello, en el marco de la regulación de las profesiones colegiadas. Nuestro ordenamiento jurídico recoge, por tanto, una reserva de ley en la configuración del ejercicio de las profesiones tituladas que debe ser

Véase el derecho de acceso a los cargos y funciones públicas que se reconoce en el art. $23 \mathrm{CE}$, respecto del que el propio TC se ha encargado de aclarar que consagra una triple dimensión del derecho: acceso, permanencia y ejercicio del cargo (véanse, entre otras, SSTC 24/1983 y 28/1984). 
interpretada como una garantía de su autonomía. Según la jurisprudencia del Tribunal Constitucional (TC) la reserva de ley que impone el art. 53.1 CE en relación con los derechos y libertades de este art. 35 comporta la existencia de un contenido esencial de estos que los garantice constitucionalmente (STC 83/1984). El legislador tiene la facultad de regular el ejercicio de las profesiones, conforme resulta de lo dispuesto por el art. $36 \mathrm{CE}$, pero teniendo en cuenta que tal regulación debe inspirarse en el criterio del interés público y tener como límite el respeto del contenido esencial de la libertad profesional (STC 42/1986).

En palabras del Tribunal Supremo (TS), la libertad de prescripción del médico, que es una auténtica manifestación de la libertad de ejercicio profesional consagrada en el art. $36 \mathrm{CE}$, no puede ser restringida en modo alguno ni por una resolución o circular de un director provincial del INSALUD, ni por un reglamento de la Administración. Solo la ley puede restringir esa libertad fundamental. Una cosa es controlar e inspeccionar la labor del médico de la Seguridad Social y otra muy distinta es ordenar cómo debe ejercer el médico su profesión al valorar si ha prescrito de forma idónea. Y ello es así porque tal idoneidad o no del médico para prescribir, diagnosticar o fijar el tratamiento del enfermo constituye una esfera del contenido esencial de su derecho a ejercer libremente la profesión, en la que no puede entrar la Administración por la vía de dictar autos, resoluciones, circulares o instrucciones (STS de 18 de octubre de 1989, art. 7411) $)^{2}$. Sin embargo, el propio TS ha matizado que tal reserva de ley no impide constitucionalmente que la ley defiera a la potestad reglamentaria, o el Gobierno ejerza — todo dentro de su ámbito constitucional conforme al art. 97-, la regulación de algunas precisiones propias, de este modo en su función complementaria del legislativo (STS de 31 de octubre de 2000, art.10045).

La libertad profesional, si bien no aparece mencionada en el Convenio Europeo de Derechos Humanos, sí es incorporada a la Carta de Derechos Fundamentales de la Unión Europea en su art. 15.1 que señala que «Toda persona tiene derecho a trabajar y a ejercer una profesión libremente elegida o aceptada».

En el ámbito de la medicina, la libertad de actuación del médico es indispensable para garantizar la calidad del acto médico y para fortalecer la relación del médico con el paciente; y cobra especial relevancia dados los valores sobre los que incide dicha profesión. Sin embargo, es precisamente la libertad médica la que ha presentado en las últimas décadas un mayor debate acerca de

2 En similares términos se expresa la STS de 27 de noviembre de 1989, Sala 3.a , art. 8327. 
su eficacia y límites. No se trata de un debate que afecte con carácter general a las profesiones liberales, sino singularmente a la profesión médica. Ello se debe, fundamentalmente, a dos fenómenos que se desarrollan a partir de la segunda mitad del siglo xx y que inciden notablemente, como vamos a ver, en dicha libertad:

En primer lugar, el desarrollo del concepto de Estado social y dentro de este del sistema público de salud que transforma la profesión médica en una profesión incardinada dentro del propio sistema. Así, de una relación tradicionalmente bilateral (médico y paciente) y privada se pasa a una relación trilateral y pública en la que participa activamente el propio sistema, es decir, la autoridad pública gestora del servicio. Si la libertad de actuación del médico puede alcanzar su máxima expresión en aquella relación, siempre, obviamente, que se guíe por el mejor interés del paciente, no ocurre ya lo mismo cuando la relación médico-paciente se desarrolla dentro de un sistema público de salud con recursos limitados y con exigencias de distribución justa de estos. El derecho a la protección de la salud reconocido en el art. 43 CE y el derecho a la atención sanitaria establecido en el art. 1 de la Ley 14/1986, de 25 de abril, General de Sanidad, se sustentan, en su regulación y ejercicio, en la acción mutua e interrelacionada de tres elementos claves: el usuario, destinatario del derecho; la Administración pública; responsable de su tutela a través de la organización de los servicios necesarios; y los profesionales sanitarios que actualizan el deber impuesto a la institución (Beato Espejo, 1994: 59).

En segundo lugar, el principio de autonomía del paciente que exigirá del médico respetar no tanto su libertad, sino la del paciente. Mientras que en la concepción tradicional paternalista de la medicina el punto de partida de las argumentaciones justificantes eran la naturaleza, las obligaciones y las prerrogativas del médico, en la actual concepción del modelo de relación basado en la autonomía del paciente y del consentimiento informado, el prius son los derechos del paciente y el derecho del médico pasa a ser un posterius (Alemany, 2011: 746).

El principio de autonomía que preside desde hace pocas décadas la relación médico-paciente implica que el médico deberá obtener el consentimiento informado del paciente con anterioridad a llevar a cabo el acto médico. Frente a una relación en la que primaba la decisión del médico, quien estaba más cualificado profesionalmente para determinar qué opción terapéutica era la más conveniente para el paciente — principio de beneficencia y mejor interés del paciente-, nos encontramos ahora ante una relación asentada en el principio de autonomía; es decir, en la decisión única y exclusiva del paciente. En este sentido, el tratamiento y cuidado médico poseen una dimensión subjetiva que solo puede ser apreciada y decidida por el paciente. El médico sabe, por su profesión, lo que con carácter general supone, en cuanto a riesgos, beneficios y 
molestias, un tratamiento. Sin embargo, en qué medida este afecta al proyecto de vida o al bienestar del paciente es algo que solo puede conocer este último.

En todo caso, la aparición del principio de autonomía no es exclusiva de la relación médico-paciente, sino que este ha alcanzado muchos otros ámbitos de la realidad social y cultural. En las sociedades con economía de mercado, un valor de gran importancia es la satisfacción de los deseos individuales; y para ello reviste sustancial importancia la autonomía. La eclosión del principio de autonomía constituye un rasgo característico de nuestra sociedad contemporánea, aunque si ha afectado singularmente a una relación profesional, ha sido precisamente a la del médico y paciente como reacción al paternalismo que esta recogía con anterioridad y a los propios valores e intereses en juego en el ámbito del tratamiento médico. La especial incidencia de la autonomía en el ámbito sanitario viene justificada por el hecho de que la relación médico-paciente ha estado tradicionalmente dominada por el paternalismo, quedando el paciente, en la mayoría de las ocasiones, al margen de la toma de decisión acerca de los tratamientos y cuidados. Es decir, constituía un ámbito en el que la autonomía era frecuentemente soslayada, incluso, en un mayor grado que en otros ámbitos de la sociedad.

En definitiva, en el presente trabajo pretendemos preguntarnos qué papel ha de desempeñar la libertad de actuación médica cuando esta queda enmarcada dentro del contexto de un sistema público de salud y cuando ha de venir en gran medida determinada por la autonomía, no ya exclusiva del profesional, sino del paciente. A este respecto, cabe plantearse si estamos ante un mero vestigio propio de un concepto de relación médico-paciente que se ha visto ya superado por el nuevo marco en el que habitualmente se desenvuelve o si, por el contrario, tal autonomía del médico ha de mantener aún, incluso en el marco de una relación pública de servicio, vigencia. La pregunta que pretendemos resolver es, en definitiva, qué ámbito de inmunidad y, por ende, de operatividad puede reconocérsele a la libertad de actuación médica como expresión concreta de la libertad profesional, en un contexto bien distinto a aquel en el que surge tal libertad. Se trata de una garantía innata al ejercicio de la profesión médica y que, por tanto, mantiene su vigencia aún cuando quede sujeta a nuevos límites y precisiones o, por el contrario, se trata de un mero mito que ha de carecer de verdadera virtualidad en el momento actual, fuera de las relaciones puramente privadas entre médico y paciente.

Nuestro debate no debe quedar únicamente circunscrito a la sanidad pública, ya que la constricción de la autonomía derivada del control del gasto se produce también en el marco de la prestación de servicios médicos por cuenta ajena. Lo mismo puede decirse del principio de autonomía del paciente, el cual, como se recoge en la Ley 41/2002, de 14 de noviembre, básica reguladora de la Autonomía del Paciente y de Derechos y Obligaciones en Materia 
de Información y Documentación Clínica, afecta tanto a la medicina pública como a la privada (art. 1). Pese a ello, vamos a referirnos principalmente al ámbito público porque es precisamente en este donde la libertad de actuación médica queda especialmente afectada al tener que insertarse en un contexto de prestación pública en el que deben ser atendidos intereses generales no coincidentes en muchas ocasiones con los del profesional y tampoco con los del propio paciente.

En el marco de nuestro debate haremos una especial referencia a la objeción de conciencia porque, precisamente, esta es una expresión de dicha libertad de actuación médica, sobre todo, abordando el reciente debate suscitado principalmente por los cambios introducidos en el Sistema Nacional de Salud por el Real Decreto Ley 16/2012 en relación con la asistencia sanitaria gratuita a los inmigrantes sin papeles, lo que ha dado lugar a diversas expresiones de objeción de conciencia positiva, lo que contrasta con una libertad que tradicionalmente se ha expresado en un sentido negativo, como omisión del cumplimiento de un deber legal positivo.

\section{LA DOBLE DIMENSIÓN DE LA LIBERTAD DE ACTUACIÓN MÉDICA}

Como acabamos de comentar, la libertad de actuación médica aparece consagrada como un derecho fundamental en el art. $35 \mathrm{CE}$, dentro de la libertad de ejercicio de las profesiones. Como tal derecho fundamental, dentro de esta podemos apreciar dos dimensiones, la subjetiva y objetiva, las cuales es importante distinguir a la hora de poder debatir acerca de la eficacia y límites de dicha libertad.

La dimensión subjetiva viene referida al haz interno que fundamenta el derecho, conectándolo directamente con el estatus jurídico o libertad que, a través de este, se confiere a su titular. Así, puede afirmarse que la libertad de actuación médica conecta directamente con la dignidad y el libre desarrollo de la personalidad que el ejercicio de una profesión implica. Reconocerle libertad al médico supone atribuirle un espacio de desarrollo de su propio proyecto vital dentro del que se incardina el proyecto profesional. El profesional al que no se le permite actuar con libertad es tratado indignamente y vejado, lo que lo condena al aislamiento social y al empobrecimiento espiritual.

La dimensión objetiva conecta el derecho con el valor social que este representa y con el fin externo hacia el que el derecho se orienta. En este caso, la libertad de actuación médica no solo es una garantía del desarrollo del propio proyecto vital de su titular, sino, más aún, es una garantía de un sistema social de valores. Si la primera dimensión es fundamentadora por su conexión con la dignidad, la segunda es más instrumental, ya que, a través del respeto 
al derecho, se garantiza un sistema de convivencia en unos valores de libertad y justicia.

Tal doble dimensión de los derechos y libertades ya fue reconocida por el propio TC en una de sus primeras resoluciones: los derechos fundamentales son derechos subjetivos, derechos de los individuos no solo en cuanto derechos de los ciudadanos en sentido estricto, sino en cuanto que garantizan un estatus jurídico o la libertad en un ámbito de la existencia. Pero, al propio tiempo, son elementos esenciales de un ordenamiento objetivo de la comunidad nacional, en cuanto que esta se configura como marco de una convivencia humana justa y pacífica (STC 25/1981). Pocos años después, el propio TC volvía a insistir en dicha doble dimensión: los derechos fundamentales son los componentes estructurales básicos, tanto del conjunto del orden jurídico objetivo como de cada una de las ramas que lo integran, en razón de que son la expresión jurídica de un sistema de valores que, por decisión del constituyente, ha de informar el conjunto de la organización jurídica y política; son, en fin, como dice el art. 10 $\mathrm{CE}$, el «fundamento del orden jurídico y de la paz social». De la significación y finalidades de estos derechos dentro del orden constitucional se desprende que la garantía de su vigencia no puede limitarse a la posibilidad del ejercicio de pretensiones por parte de los individuos, sino que ha de ser asumida también por el Estado. Por consiguiente, de la obligación del sometimiento de todos los poderes a la CE no solamente se deduce la obligación negativa del Estado de no lesionar la esfera individual o institucional protegida por los derechos fundamentales, sino también la obligación positiva de contribuir a la efectividad de tales derechos, y de los valores que representan, aun cuando no exista una pretensión subjetiva por parte del ciudadano (STC 53/1985).

De tal distinción entre dos dimensiones pueden extraerse dos consideraciones de interés a la hora de valorar en qué medida la libertad de actuación médica puede ser limitada.

En primer lugar, como libertad que conecta con la dignidad y el libre desarrollo de la personalidad, cualquier límite que pueda imponerse a esta ha de respetar un mínimo o núcleo esencial del derecho. No cabría en modo alguno aceptar un límite que desdibuje los rasgos mínimos que caracterizan a dicha libertad so pena de infringir el principio de proporcionalidad y más específicamente el subprincipio de proporcionalidad en sentido estricto. Todo límite ha de respetar un mínimo haz de facultades que hagan reconocible dicha libertad de acuerdo con las facultades mínimas que integran su contenido. El mínimo o núcleo esencial de la libertad de actuación médica ha sido interpretado por la doctrina con la imagen social de cada profesión (Villar Rojas, 1997: 108), lo que se traduciría en aquellos rasgos específicos que dentro de cada sociedad identifican y singularizan a cada profesión, de manera que, si suprimimos alguno de ellos, dicha imagen desaparece. 
En segundo lugar, cualquier límite que pueda imponerse a la libertad de actuación médica, aun cuando venga sustentado, como no puede ser de otro modo, en el interés general, debe atender a la dimensión objetiva que tal libertad cumple, precisamente, en satisfacción de dicha dimensión objetiva o social del derecho. El médico se ve investido de dicha libertad en el ejercicio de su profesión no solo como una expresión de su dignidad y libre desarrollo de la personalidad, sino como una garantía de los valores sociales que, a través de esta, se satisfacen. La libertad de actuación médica es, en sí misma, una expresión de la libertad; y la libertad es uno de los principios fundadores de nuestro orden constitucional como se proclama en el art. 1.1 CE. Garantizando la libertad profesional del médico, se garantiza dicho principio y, por ende, una sociedad más respetuosa con el propio principio de democracia.

La dimensión objetiva de la libertad de actuación médica nos remite también a su carácter instrumental, de manera que a través de esta se protege la dignidad del profesional, el interés social que esta representa en nuestro sistema de valores y, además, al propio paciente. Tal libertad se reconoce como una garantía de la protección de los derechos sobre los que incide el tratamiento médico, que no son otros que la vida y la integridad. Garantizando la libertad del médico, se protege la vida e integridad del paciente. Si la libertad médica debe atender, para ser ejercida correctamente, el mejor interés del paciente, puede fácilmente afirmarse que dicha libertad es, como hemos explicado antes, la garantía de su salud.

De este modo, cualquier límite a tal libertad no solo debe ser valorado desde la perspectiva del profesional que ve obstaculizado su propio proyecto de vida profesional, sino, también, desde la perspectiva del propio paciente en la medida en que aquel puede afectar a su vida e integridad. $\mathrm{Y}$, a este respecto, debemos recordar que el TC tiene declarado que la protección constitucional de la vida y de la integridad personal (física y moral) no se reduce al estricto reconocimiento de los derechos subjetivos necesarios para reaccionar jurídicamente frente a las agresiones a ellos inferidas, sino que, además, contiene un mandato de protección suficiente de aquellos bienes de la personalidad dirigido al legislador y que debe presidir e informar toda su actuación (STC $181 / 2000)$.

\section{LA REGULACIÓN DE LA LIBERTAD DE ACTUACIÓN MÉDICA}

La Ley 14/1986, de 25 de abril, General de Sanidad, constituye el principal antecedente en el que se incorpora una referencia, aunque sucinta, a la libertad de actuación médica. Su art. 88 proclama que «Se reconoce el derecho al ejercicio libre de las profesiones sanitarias, de acuerdo con lo establecido en los 
artículos 35 y 36 de la Constitución». Previamente a dicha norma, el Decreto 2065/1974, de 30 de mayo, por el que se aprueba el texto refundido de la Ley General de la Seguridad Social, cuyos artículos relativos a la asistencia sanitaria no han sido derogados, dispone en su art. 105 que «1. La asistencia farmacéutica comprenderá las fórmulas magistrales, especialidades y efectos o accesorios farmacéuticos que se prescriban por los facultativos de la Seguridad Social», añadiendo en el siguiente art. 106 sobre la libertad de prescripción que «Los facultativos encargados de los servicios sanitarios de este Régimen General podrán prescribir libremente las fórmulas magistrales y las especialidades farmacéuticas reconocidas por la legislación sanitaria vigente que sean convenientes para la recuperación de la salud de sus pacientes».

La previsión contenida en la Ley General de Sanidad ha sido desarrollada con mayor detalle en la Ley 44/2003, de 21 de noviembre, de Ordenación de las Profesiones Sanitarias. En su art. 4.1 se dispone que «De acuerdo con lo establecido en los artículos 35 y 36 de la Constitución, se reconoce el derecho al libre ejercicio de las profesiones sanitarias, con los requisitos previstos en esta ley y en las demás normas legales que resulten aplicables» y añade, a continuación, en su siguiente apdo. 7 que «El ejercicio de las profesiones sanitarias se llevará a cabo con plena autonomía técnica y científica, sin más limitaciones que las establecidas en esta ley y por los demás principios y valores contenidos en el ordenamiento jurídico y deontológico», y, además, de acuerdo con unos principios que describe expresamente la propia ley, que por lo que a nuestro debate interesa, deben ser destacados los dos siguientes: el principio de plasmación documental de la actuación del médico y del propio proceso asistencial en la historia clínica ${ }^{3}$ y el principio de unificación de los criterios de actuación, de acuerdo con la evidencia científica, aunque la propia ley se encarga de remarcar que los protocolos que puedan elaborarse al amparo de dicho principio serán meramente orientativos.

Así pues, la libertad de actuación médica no ampara ni faculta ni abstenerse de cumplimentar la historia clínica ni actuar al margen de los protocolos y guías que se aprueben de acuerdo con la evidencia científica, aunque, como ya hemos señalado, la propia ley se encarga de matizar que tales criterios son meramente orientadores, lo que es conforme con la idea de que los consensos que se plasman en protocolos responden a patrones de pacientes, en ocasiones

3 Este deber se recoge igualmente en la Ley 55/2003, de 16 de diciembre, del Estatuto Marco del Personal Estatutario de los Servicios de Salud, en su art. 19 l) que dispone que el personal estatutario de los servicios de salud viene obligado a «l) Cumplimentar los registros, informes y demás documentación clínica o administrativa establecidos en la correspondiente institución, centro o servicio de salud». 
estereotipados o incluidos en lo considerado una distribución de la normalidad dentro del género humano, cuando la práctica asistencial demuestra que rara vez un caso es igual a otro, y que existe un alto grado de diversidad individual dentro de ser todos humanos. Como afirma el clásico aforismo de la medicina, no existen enfermedades, sino enfermos. La necesidad de elaborar las denominadas guías de práctica clínica o protocolos clínicos surge como una respuesta a la complejidad y conflictividad del quehacer médico. El protocolo supone compartir conocimientos, pero también puede suponer desconocer que la relación médico-paciente es una relación individual; es decir, que existen no solo enfermedades, sino fundamentalmente pacientes. Dichos protocolos, expresión del progreso tecnológico y de la complejidad de la decisión clínica, constituyen también instrumentos que pueden vulnerar la autonomía del paciente, ya que, en virtud de estos, pueden quedar soslayadas las preferencias del paciente en beneficio del mejor quehacer médico.

Por ello, el protocolo no puede condicionar la actuación del médico cuando el mejor interés del paciente exija precisamente apartarse del protocolo. Así pues, el dilema que se ha venido planteando entre el mero valor orientativo de las guías de práctica clínica o su vinculación normativa, parece ya resuelto por la ley.

Debe recordarse, además, que el ejercicio protocolizado de la medicina no puede afectar al principio de autonomía de voluntad que preside la relación médico-paciente, de manera que la aplicación de una guía de buena práctica clínica no puede imponerse al paciente en contra de su criterio o voluntad. La autonomía del paciente condiciona necesariamente esta aplicación del protocolo. Lo que puede ser mejor para todos los pacientes puede no ser aceptado por un paciente concreto. Así lo han reconocido nuestros tribunales de justicia, habiendo señalado el TS que la medicina no suele presentar un único método, por más que la protocolización de los actos médicos invita a ajustarse a unas pautas seriadas de diagnóstico y tratamiento terapéutico, lo que no excluye que puedan existir otros métodos que, a no ser de uso generalizado, pueden ser igualmente utilizados si en el caso concreto se considera que pueden ser más eficaces (STS 14 de marzo de 2005, art. 3620).

La misma ley de ordenación añade unos principios que han de regir la relación entre los profesionales sanitarios y las personas atendidas por ellos y que, en cuanto tales, delimitan también la libertad de actuación médica. Así, el art. 5 recoge, entre otros, los siguientes:

- Los profesionales tienen el deber de prestar una atención sanitaria técnica y profesional adecuada a las necesidades de salud de las personas que atienden de acuerdo con el estado de desarrollo de los conocimientos científicos de cada momento y con los niveles de calidad y seguridad 
que se establecen en esta ley y el resto de normas legales y deontológicas aplicables.

- Los profesionales tienen el deber de hacer un uso racional de los recursos diagnósticos y terapéuticos a su cargo, tomando en consideración, entre otros, los costes de sus decisiones y evitando la sobreutilización, la infrautilización y la inadecuada utilización de estos.

- Los profesionales tienen el deber de respetar la personalidad, dignidad e intimidad de las personas a su cuidado y deben respetar la participación de estos en las tomas de decisiones que los afecten. En todo caso, deben ofrecer una información suficiente y adecuada para que aquellos puedan ejercer su derecho al consentimiento sobre dichas decisiones.

En definitiva, si bien la Ley de Ordenación de las Profesiones Sanitarias permite concluir que la libertad de actuación médica posee aún virtualidad, también esta delimita el contenido de tal libertad. Se consagra una libertad de actuación médica delimitada por una serie de deberes que se relacionan directamente, por un lado, con la eficacia y sostenibilidad del sistema público de salud y, por el otro, con el principio de autonomía del paciente que preside en la actualidad la relación médico-paciente. Nuestro ordenamiento jurídico, como no podía ser de otra manera, regula la libertad de prescripción médica en el marco del deber público de sostener un sistema público de protección de la salud, lo que, necesariamente, supone una importante restricción de esta.

Junto a la citada ley, el Estatuto Marco del Personal Estatutario de los Servicios de Salud, aprobado por Ley 55/2003, de 16 de diciembre, recoge entre los deberes de dicho personal los de «e) Participar y colaborar eficazmente, en el nivel que corresponda en función de su categoría profesional, en la fijación y consecución de los objetivos cuantitativos y cualitativos asignados a la institución, centro o unidad en la que preste servicios» y «k) Utilizar los medios, instrumental e instalaciones de los servicios de salud en beneficio del paciente, con criterios de eficiencia». Sin embargo, el mismo Estatuto Marco establece dentro de las infracciones muy graves la relativa a «La desobediencia notoria y manifiesta a las órdenes o instrucciones de un superior directo, mediato o inmediato, emitidas por este en el ejercicio de sus funciones» y establece una eximente a dicho deber cuando la orden o instrucción «constituyan una infracción manifiesta y clara y terminante de un precepto de una ley o de otra disposición de carácter general» (art. 72). Si bien se trata de una cláusula común a la función pública, sí que es cierto que cobra especial relevancia en el ámbito de la libertad médica si tenemos en cuenta su carácter instrumental como garante de la mejor asistencia al paciente. Dicha cláusula otorga cierto contrapeso al profesional para oponerse a aquellas medidas que puedan ser 
contrarias a la salud de los pacientes, siempre que estas no respondan a las exigencias de idoneidad, necesidad y proporcionalidad en sentido estricto.

La libertad de actuación médica aparece también recogida en el Código de Deontología Médica del Consejo General de Colegios Oficiales de Médicos de 2011, concretamente, en el art. 23.1 que proclama que «El médico debe disponer de libertad de prescripción, respetando la evidencia científica y las indicaciones autorizadas, que le permita actuar con independencia y garantía de calidad», una libertad que habrá de ser respetada por las normas de la institución (art. 46.2). El apdo. 3 de este precepto añade que «Los incentivos ligados a la prescripción tendentes a aliviar el gasto sanitario deberán tener presente la mejoría de la eficiencia salvaguardando la calidad asistencial y la libertad de prescripción", añadiendo el apdo. 5 que «El médico no puede aceptar una remuneración fundada en normas de productividad, de rendimiento horario o cualquier otra disposición que atente objetivamente contra la calidad de su asistencia».

$\mathrm{El}$ art. 7.5 manifiesta que «Siendo el sistema sanitario el instrumento principal de la sociedad para la atención y promoción de la salud, los médicos han de velar para que en él se den los requisitos de calidad, suficiencia asistencial y mantenimiento de los principios éticos. Están obligados a denunciar las deficiencias, en tanto puedan afectar a la correcta atención de los pacientes».

El mismo Código señala en el art. 21.3 que «El tiempo necesario para cada acto médico debe ser fijado por el criterio profesional del médico, teniendo en cuenta las necesidades individuales de cada paciente y la obligación de procurar la mayor eficacia y eficiencia en su trabajo».

El TS ha interpretado la libertad de actuación del médico como la facultad que tiene de escoger la solución más beneficiosa para el bienestar del paciente poniendo a su alcance los recursos que le parezcan más eficaces para el caso que se deba tratar, siempre y cuando sean generalmente aceptados por la ciencia médica, o susceptibles de discusión científica, de acuerdo con los riesgos inherentes al acto médico que practica. Añade esta resolución que el médico es, por tanto, el encargado de establecer el tratamiento terapéutico individualizado en función de la respuesta del paciente (STS de 8 de febrero de 2006, art. 544).

\section{LA AUTONOMÍA DEL PACIENTE COMO LÍMITE A LA AUTONOMÍA DEL MÉDICO}

Como ya hemos comentado al inicio de nuestro trabajo, la libertad de actuación médica debe cohonestarse con la autonomía del paciente tras proclamarse esta como el principio vehicular de la relación médico-paciente. El 
criterio técnico-científico del médico no puede imponerse sobre la voluntad del paciente. Ello no supone un nuevo límite a la libertad médica, sino un elemento que necesariamente delimita tal libertad. A este respecto, debemos recordar que el derecho a autorizar o rechazar el tratamiento médico — es decir, la propuesta efectuada por el médico en ejercicio de su libertad de actuación médica, como una expresión de la autonomía del paciente- no es un derecho que se haya creado ex novo por nuestro sistema jurídico, sino que es una manifestación en el ámbito de dicho tratamiento del derecho a la integridad física y moral del individuo consagrado en el art. 15 CE. No se trata de un nuevo límite creado ope legis a la libertad médica, sino de una expresión de un derecho fundamental también proclamado en el mismo texto constitucional.

Todo ello lo recoge el TC en su Sentencia 37/2011 cuando declara que el derecho del art. $15 \mathrm{CE}$ protege la inviolabilidad de la persona no solo contra los ataques dirigidos a lesionar su cuerpo o espíritu, sino también contra toda clase de intervención en esos bienes que carezca del consentimiento de su titular, lo que conlleva, por tanto, una facultad negativa que implica la imposición de un deber de abstención de actuaciones médicas, salvo que se encuentren constitucionalmente justificadas, y, asimismo, una facultad de oposición a la asistencia médica, en ejercicio de un derecho de autodeterminación que tiene por objeto el propio sustrato corporal, como distinto del derecho a la salud o a la vida.

El TC afirma que el derecho a la integridad física y moral resultará afectado cuando se imponga a una persona asistencia médica en contra de su voluntad, y ello pese a que el citado art. 15 no contiene una referencia explícita al consentimiento informado, lo que no implica que este instituto quede al margen de la previsión constitucional de protección de la integridad física y moral. Como el TC había ya declarado antes (SSTC 212/1996 y 116/1999), los preceptos constitucionales relativos a los derechos fundamentales y libertades públicas pueden no agotar su contenido en el reconocimiento de estos, sino que, más allá de ello, pueden contener exigencias dirigidas al legislador en su labor de continua configuración del ordenamiento jurídico, bien en forma de las llamadas garantías institucionales, bien en forma de principios rectores de contornos más amplios, bien, como enseguida veremos, en forma de bienes jurídicos constitucionalmente protegidos.

Para el TC, las actuaciones médicas llevan implícita una posibilidad de afección a la integridad personal protegida por el art. $15 \mathrm{CE}$, en la medida en que este tutela la inviolabilidad de la persona contra toda intervención en su cuerpo, de manera que es preciso arbitrar los mecanismos necesarios para garantizar la efectividad del derecho dentro de ese ámbito, cohonestándolo con la función y finalidad propias de la actividad médica. La garantía de la efectividad del derecho en el ámbito médico implica que cualquier actuación 
que afecte a la integridad personal, para resultar acorde con dicho derecho, se ha de encontrar consentida por el sujeto titular del derecho o debe encontrarse constitucionalmente justificada.

En similares términos se expresa el TS cuando manifiesta que la decisión del médico tiene como destinatario la vida, la integridad humana y la preservación de la salud del paciente (STS 8.II.2006, art. 544).

Por lo tanto, la libertad de actuación médica se encuentra, también, no limitada, sino delimitada por el derecho a la integridad física y moral del paciente que se consagra en el art. $15 \mathrm{CE}$ y del que es expresión el derecho a autorizar o rechazar el tratamiento que recoge actualmente la Ley de Autonomía del Paciente.

¿Mantiene, como antes nos hemos planteado, un mínimo esencial o núcleo tal libertad frente a la autonomía del paciente? Creemos que sí, y esta vendría determinada por el derecho del médico, dentro de su libertad profesional, de no llevar a cabo acciones positivas contrarias a su criterio. Este sería el caso en el que el paciente exigiera del médico llevar a cabo un tratamiento que fuera contrario a la evidencia científica o que el profesional considerara menos idóneo o innecesario según la lex artis ad hoc. En este caso, prima la autonomía científica del médico frente a la autonomía del paciente, dado que el paciente no está legitimado para obligar al médico a actuar en contra de la lex artis ad hoc (Beltrán Aguirre, 2016: 118). La autonomía habilita al paciente a negarse a un determinado tratamiento aun con riesgo de su vida, pero no lo faculta para exigir la aplicación de un tratamiento contrario a dicha evidencia científica. Admitir lo contrario implica exigir al médico que infrinja uno de los principales deberes éticos (o, incluso, podríamos decir el principal deber ético) que informa de su conducta: el de primum non nocere, que la bioética contemporánea expresa como principio de no maleficencia.

Nuestro argumento vendría sustentado por el propio tenor de la Ley de Autonomía del Paciente que en su art. 2 dispone que «El paciente o usuario tiene derecho a decidir libremente, después de recibir la información adecuada, entre las opciones clínicas disponibles, teniendo derecho a negarse al tratamiento, excepto en los casos determinados en la Ley». La misma conclusión se alcanza con la lectura del art. 11 de la misma ley, en el que se regula la institución de las instrucciones previas. Dicho precepto establece en su apdo. 3 que la lex artis opera como un límite a la voluntad del paciente plasmado en tal documento de manera que el médico no estaría obligado a respetar tal voluntad cuando fuera contraria a la lex artis del caso concreto.

Así pues, la ley consagra un deber de omisión sobre el médico, pero, en modo alguno, un deber de acción, salvo, claro está que el médico haya ejercido incorrectamente su autonomía, apartándose, señala el TS, de los recursos que le parezcan más eficaces al caso a tratar, siempre y cuando sean generalmente 
aceptados por la ciencia médica o susceptibles de discusión científica (STS de 8 de febrero de 2006, art. 544). Conforme proclama el TS, el paciente no tiene derecho de opción en relación con la concreta actuación médica (STS de 30 de abril de 2013, art. 152538), sino que ostentaría un derecho a exigir la abstención del profesional.

En definitiva, la autonomía del paciente que preside la relación de este con el médico no ha supuesto una completa alteración de la libertad de actuación del médico, el cual conserva en virtud del principio de no maleficencia la facultad de negarse a llevar a cabo tratamientos que considere contrarios al mejor interés del paciente o que sean contrarios a la evidencia científica. Sobre el médico recae un deber de abstención en respeto de la integridad física y moral del paciente, pero no un deber de acción en contra de su autonomía científica, siempre que esta venga fundamentaba en la evidencia científica contrastada.

\section{EL SISTEMA PÚBLICO DE SALUD COMO LÍMITE A LA AUTONOMÍA DEL MÉDICO}

Como ya hemos apuntado antes, la inserción de la prestación sanitaria dentro de un sistema público de salud exige una distribución y una ordenación de los recursos que necesariamente han de incidir en la libertad de actuación médica. El médico no será ya ese tradicional profesional liberal que responde en exclusiva al mejor interés del paciente, sino un agente público que, como tal, participa activamente en la distribución de los recursos públicos; y la pregunta es si las potestades de autoorganización del servicio de las que se encuentra investido el poder público sanitario — más aún, en los contextos económicos como el que estamos viviendo desde hace casi una década en la que los recursos son muy limitados - afectan negativamente al libre ejercicio de la profesión médica o, incluso, si hacen que esta pierda ya actualidad.

Desde una perspectiva puramente conceptual, si la libertad médica ostenta una doble dimensión - como antes hemos expuesto, que conecta tanto con la dignidad y el libre desarrollo de la personalidad del individuo (en este caso, el médico) como con los valores superiores que fundamentan nuestro orden constitucional (la libertad médica es en esencia expresión del principio de libertad) y, además, tiene una naturaleza instrumental que la convierte en una garantía de la mejor asistencia que ha de recibir el paciente-, es obvio que el sistema público de salud podrá limitar dicha libertad en función de las necesidades del interés general, pero, en modo alguno, suprimir esta o afectar a su núcleo esencial de manera que los rasgos que la caracterizan sean ya inidentificables. 
Como tal libertad constitucionalmente consagrada, cualquier pretensión de limitarla deberá superar el test de proporcionalidad, mostrando que el interés general que fundamenta la limitación no solo está previsto legalmente, sino que, además, es idóneo, necesario y proporcional en sentido estricto. A este respecto, y por lo que se refiere al primero de los requisitos, es importante recordar que nuestro ordenamiento jurídico ha explicitado y desarrollado normativamente un importante número de intereses generales bajo la forma de deber legal que le permiten al legislador adoptar medidas limitadoras de la libertad de actuación médica con cierta facilidad, todo ello, en garantía del deber que le impone el art. $43 \mathrm{CE}$. Como vimos anteriormente, si bien la Ley de Ordenación de las Profesiones Sanitarias consagra, como no podía ser de otro modo a la vista de lo dispuesto por los arts. 35 y $36 \mathrm{CE}$, la libertad médica, al mismo tiempo establece diferentes reglas para delimitarla. En estas, podemos destacar el deber de hacer un uso racional de los recursos diagnósticos y terapéuticos a su cargo, tomando en consideración, entre otros, los costes de sus decisiones, y evitando la sobreutilización, la infrautilización y la inadecuada utilización de estos (art. 5).

En todo caso, a la hora de hablar de límites, es importante valorar ab initio si dichos límites son realmente límites en sentido propio o límites internos que delimitan el derecho. Como hemos visto antes, si bien es la propia CE la que consagra la libertad de actuación médica a través de la proclamación de la libertad profesional en sus arts. 35 y 36, también esta establece la garantía institucional de un sistema de protección de la salud de manera que puede perfectamente afirmarse que la libertad de actuación médica no podrá ejercerse en perjuicio o detrimento de dicho sistema. Se reconoce tal libertad en el marco de un sistema público de protección de la salud.

Por ello, muchas de las medidas que puedan adoptar los poderes públicos sanitarios no serán ya límites a la libertad médica que, como tales, deben quedar sujetos a su valoración a través del principio de proporcionalidad, sino delimitaciones de un derecho que, como hemos comentado, se reconoce dentro de los límites de la garantía institucional que se proclama en el art. $43 \mathrm{CE}$. Sin embargo, tal poder de delimitación de la libertad de actuación médica de acuerdo con lo dispuesto en el art. 43 CE no podrá afectar al derecho de manera que lo vacíe de contenido ni imponer medidas que no sean idóneas o necesarios para el logro de tal fin.

El TS en su Sentencia de 31 de octubre de 2000 (art. 10045) reconoce sin ambages que el ejercicio de la libertad de la actuación médica en el ámbito concreto de la prescripción de medicamentos ha de cohonestarse dentro de un sistema público de protección de la salud con el principio de uso racional de los medicamentos que consagra nuestro ordenamiento jurídico y que se encuentra auspiciado por la Organización Mundial de la Salud y el Consejo de 
Europa. Este principio exige que se consuman los medicamentos necesarios y, de ellos, los de mejor balance utilidad terapéutica/coste; determinándose, de este modo, la inclusión y la exclusión de los medicamentos sufragados con fondos públicos, atendiendo a la eficacia que deriva del adecuado cumplimiento del fin de la acción sanitaria pública cohonestada con la eficacia real del gasto inversor, excluyendo los productos cuyas indicaciones sean meramente sintomatológicas o para síndromes menores, así como aquellos medicamentos cuya financiación pública no se justifique o se estime no necesaria. Tal límite a la libertad de prescripción viene exigido por el carácter limitado de los recursos económicos para sufragar los productos farmacológicos existentes en el mercado, no pudiendo prescindirse mediante invocación a la libertad de prescripción médica de la realidad social y económica en que se inserta ese modo profesional.

Recuerda el TS que los derechos, incluso los de reconocimiento constitucional, no son absolutos, y que la libertad de prescripción ha de venir condicionada por el deber de los poderes públicos derivado del art. $43 \mathrm{CE}$ de mantener un sistema público de salud asequible a todos en condiciones de igualdad. El uso racional de los medicamentos en el Sistema Nacional de Salud, de la que forma parte su financiación pública, es una exigencia lógica de un sistema público que, en defensa de los intereses generales, ha de buscar el equilibrio entre la racionalización del gasto, la limitación de los recursos, la gravedad de las patologías, la necesidad de ciertos colectivos y la utilidad terapéutica y social de los medicamentos.

En el fondo, el TS no está justificando una limitación de la libertad de actuación médica en el marco concreto de la prescripción de medicamentos sobre la base del interés público en el mantenimiento de un interés público, sino delimitando tal libertad que es proclamada por los arts. 35 y $36 \mathrm{CE}$.

En similares términos se ha expresado la reciente sentencia del TC en la que se enjuicia la constitucionalidad del Real Decreto Ley 16/2012, por lo que se implementaron diferentes medidas de racionalización del gasto sanitario, empezando por la propia definición de la condición de beneficiario del sistema público de salud. Pues bien, el TC en fecha de 21 de julio de 2016 ha declarado que el legislador posee en una destacada libertad de configuración del derecho consagrado en el art. 43.2 CE, dada la ubicación sistemática de este precepto de conformidad con lo dispuesto en el art. 53.3. La sostenibilidad del sistema sanitario público impone a los poderes públicos la necesidad de adoptar medidas de racionalización del gasto sanitario, necesarias en una situación caracterizada por una exigente reducción del gasto público, de manera que las Administraciones públicas competentes tienen la obligación de distribuir equitativamente los recursos públicos disponibles y favorecer un uso racional de este sistema (con cita del ATC 96/2011, de 21 de junio, FJ 6). 
En definitiva, podemos afirmar que la libertad de actuación médica, si bien es proclamada por nuestra CE como un verdadero derecho fundamental, debe ser interpretada de conformidad con el deber que los poderes públicos tienen de mantener un sistema de público de salud según se deriva del art. 43 CE. Interpretar la libertad de actuación médica, es decir, el derecho consagrado en el art. 35 CE de conformidad con tal deber que establece el art. 43 no es limitar el derecho, sino delimitar el contorno de eficacia que este ha de poseer dentro de un sistema público de salud. La libertad profesional del médico se encuentra delimitada constitucionalmente por la previsión contenida en el art. 43.

Sin embargo, la propia $\mathrm{CE}$ - y así lo ha proclamado su máxime intérprete- garantiza un mínimo esencial o núcleo del derecho que ha de conservarse, es decir, unos rasgos mínimos que caracterizan y singularizan al derecho y lo hacen reconocible ¿Qué límite han de encontrar los poderes públicos en su función de delimitación de la libertad de actuación médica en garantía del sistema público de salud? La libertad médica es instrumental en la medida en que es garante de la calidad de la asistencia a los pacientes y, en cuanto tal, incide directamente sobre su derecho a la vida e integridad física y psíquica. Dicha característica es la que creemos que debe permitir cierto poder de resistencia al médico frente a la decisión del poder público sanitario cuando las decisiones de este puedan incidir directamente en la salud o integridad de los pacientes.

Así pues, en garantía de los fines instrumentales que persigue necesariamente la libertad de actuación médica y, sobre todo, de los valores que a través de esta se protegen, vida e integridad física y psíquica de los pacientes, es importante establecer los mecanismos — que permitan conjugar las facultades de organización y racionalización del gasto- de los que debe dotarse a los poderes públicos sanitarios en garantía de la sostenibilidad del sistema público de salud conforme exige el art. 43 con dicha libertad. Entre estos mecanismos de contrapeso pueden destacarse aquellos que permiten al médico adoptar decisiones que se aparten del criterio general establecido, siempre que ello venga singularmente exigido por el mejor interés del paciente (en realidad, se trataría de darle operatividad al principio de equidad en el marco sanitario) y así, por ejemplo, poder prescribir un medicamento o una prueba diagnóstica más cara de la establecida, con la debida carga de informar de los motivos de dicha decisión médica. Este deber de informar no supone una limitación irrazonable de su libertad, siempre que la valoración, obviamente, se realice con criterios terapéuticos, no económicos, ni administrativos. Se trata de una medida que permite controlar el gasto sin perjuicio ni del usuario, en la medida en que, de ser aprobado, obtendrá la financiación pública de lo prescrita, ni del profesional, que podrá actuar conforme a su leal saber y entender (Villar Rojas, 1997: 
110). Ello no vendría exigido tanto por la exigencia de respetar el núcleo esencial de la libertad médica como por la de proteger los valores que se garantizan o sobre los que incide la decisión médica. Si bien las medidas de racionalización del gasto sanitario son siempre necesarias y los recursos, públicos y privados, siempre serán limitados para atender las necesidades asistenciales de todos, es preciso establecer también un equilibrio entre el control del gasto y la garantía de que cada uno recibe la asistencia que necesita. En consecuencia, en la adopción de esas medidas, es preciso ponderar siempre dos principios: el primero, cada ciudadano debe recibir la asistencia que necesita, ni más, ni menos, y, el segundo, debe existir siempre margen para la libertad de prescripción: no existe el hombre normal, lo estándar es algo conceptual, concretado en cada momento y cambiante, como no existe la enfermedad estándar más que los libros, cada enfermo evoluciona con su patología de modo diferente, de ahí que las medidas de racionalización, para no vulnerar la libertad de prescripción, requieran siempre de un mecanismo que permita la excepción por razones terapéuticas (Villar Rojas, 1997: 111 y 112).

Tal mecanismo de excepción o contrapeso se ha visto reconocido por el propio TC. En su Auto de 12 de diciembre de 2012, el TC señala que la resolución de estos conflictos exige realizar un juicio de ponderación entre el derecho a la vida y a la integridad física y moral que integra, asimismo, el derecho subjetivo individual a su salud personal y la gestión del soporte económico que haga posible su cotidiana consecución, sin perjuicio del deber de todos los poderes públicos de garantizar a todos los ciudadanos el derecho a la protección de la salud. Tal ponderación exige colocar, de un lado, el interés general configurado por el beneficio económico asociado al ahorro vinculado a las medidas adoptadas por el Estado y, de otro, el interés general de preservar el derecho a la salud consagrado en el art. $43 \mathrm{CE}$, sin perjuicio de que esa contraposición también tiene proyecciones individuales, puesto que la garantía del derecho a la salud no solo tiene una dimensión general asociada a la idea de salvaguarda de la salud pública, sino también una dimensión particular conectada con la afectación del derecho a la salud individual de las personas receptoras de las medidas adoptadas por los Gobiernos estatal y autonómico...", de modo que

[...] si además del mandato constitucional, se tiene en cuenta, como ya lo ha hecho este Tribunal, la vinculación entre el principio rector del Art. 43 y el Art. 15 de nuestra Carta Magna — que recoge el derecho fundamental a la vida y a la integridad física y moral en el sentido de lo reconocido por el Tribunal Europeo de Derechos Humanos-, resulta evidente que los intereses generales y públicos, vinculados a la promoción y garantía del derecho a la salud, son intereses asociados a la defensa de bienes constitucionales particularmente sensibles [...] poseen una importancia 
singular en el marco constitucional, que no puede verse desvirtuada por la mera consideración de un eventual ahorro económico que no ha podido ser concretado.

Tal doctrina del TC ha sido ya aplicada por los tribunales ordinarios para resolver conflictos concretos entre el derecho a la protección de la salud y el deber público de sostener un sistema público de salud. Así, puede verse la Sentencia del Tribunal Superior de Justicia de Galicia (TSJG) de 12 de abril de 2013, art. 675, en la que se resuelve el recurso presentado frente a la previa y eventual inactividad del Servicio Gallego de Salud (SERGAS), consistente en la no dispensación efectiva de un medicamento (en este caso, Soliris, que contiene el principio activo Eculizumab) para tratar una rara patología que aquejaba al reclamante (hemoglobinuria paroxística nocturna). El TSJG señala —apoyándose en la doctrina del TC y tras realizar el correspondiente juicio de ponderación- lo siguiente:

[..] sí se ha producido una vulneración mediata del art. 15 ab initio de nuestra Carta Magna por parte de aquella Administración institucional-autonómica, al denegársele de facto a dicho paciente promovente y mediante su injustificada inactividad al respecto la dispensación de aquel fármaco inclusive médico-oficialmente interesado, en cuanto única opción terapéutico-medicamentosa autorizada y homologada en el mercado farmacéutico a fin de precaverle no ya un riesgo vital inherente a las trombosis o aún a los daños colaterales inherentes a la prolongación de la terapia que hasta ahora se le aplica, sino en cuanto única alternativa medicamentosa susceptible de cronificar su rara patología y hacerle llevar una vida prácticamente normal, de modo que dicho principio medicamentoso conocido como ECULIZUMAB no solo le resulta vital para conjurar terceras patologías asociadas a la trombosis — parálisis; paresias; ceguera, etc.—, sino al constituir en suma una opción médica eficaz a fin de hacerle dejar de llevar una asténica y "perra» vida - permítasenos decir aún de modo coloquial y a título de claridad fáctico-expositiva-, para permitirle obtener a dicho paciente promovente y ahora ad quem apelante don Alonso una calidad de vida normal y por completo asimilable a la de las personas sanas ajenas a dicha rara patología.

En todo caso, el principal motivo que justifica la estimación del recurso enlaza con la falta de motivación de la decisión de denegar la prescripción con cargo al sistema público del medicamento, como se deduce del propio tenor de la sentencia: «Semejante vulneración mediata por aquel Ente institucional-autonómico de un derecho fundamental invocado - aquí aquel art. 15 ab initio de nuestra Carta Magna- [...] enlaza sin dificultad con la catarata de anomalías procedimentales y de fondo que han presidido la desviada y siempre omisiva actuación del Servicio Gallego de Salud (SERGAS)», añadiendo el TSJG que «semejante inactividad prestacional por parte de aquella Admi- 
nistración institucional-sanitaria se encuentra viciada ab initio y en un mero plano formal siquiera sea a título de falta de motivación —al igual que acaece con todo género de actuaciones presuntas-, con una patente infracción por ende del expreso tenor del art. 54,1 a), b) y f) de la Ley 30/1992, de 26 de noviembre, del Régimen Jurídico de las Administraciones públicas y del Procedimiento Administrativo Común, ya que precisamente prescribe que «serán motivados, con sucinta referencia de hechos y fundamentos de derecho - entre otros- a) Los actos que limiten derechos subjetivos o intereses legítimos. b) Los que resuelvan..., reclamaciones previas a la vía judicial y f) Los que se dicten en el ejercicio de potestades discrecionales, así como los que deben serlo en virtud de Disposición legal o reglamentaria expresa».

Así pues, más que la vulneración de la exigida proporcionalidad, lo que la Sala imputa a la Administración es la infracción del principio de racionalidad formal, de manera que no se ha suministrado un criterio técnico-científico que permita contrarrestar la solicitud del paciente:

[...] si se entra a valorar aquellos ulteriores argumentos denegatorios a la postre y harto tardíamente esgrimidos en el Oficio, Informe o aún Resolución de fecha 1 de agosto de 2011 - como quiera que se pueda denominar a la documental obrante al folio 8 y vto. del Expediente-, suscrito por la Sra. Presidenta de la Comisión Autonómica Central de Farmacia y Terapéutica (CACFT), adscrita a la Subdirección de Farmacia de la Dirección de Asistencia Sanitaria de la Consellería de Sanidade de la Xunta de Galicia, no cabe decir otra cosa que en cuanto a su fondo científico se encuentra viciada por equivocada y aún actualmente superada —como luego se aludirá-, sin perjuicio de que su contenido inclusive incurra en nulidad competencial al apartarse también del exclusivo ámbito de asesoramiento técnico-interno y de la mera elaboración de recomendaciones que precisamente le atribuyen los arts. 1; 2 y 3 «ab initio» de la Orden de fecha 9 de abril de 2010, de la Consellería de Sanidade (DOGA núm. 71/10, de 16 de abril), por la que se establece su composición, organización y funcionamiento, de modo que el extralimitado contenido ejecutivo-denegatorio de aquel precitado Informe de fecha 1 de agosto del 2011 resulta viciado de nulidad $a b$ radice —en cuanto conculca aquel art. 15 ab initio de nuestra Carta Magna-, conforme al art. 62,1 a); de aquella Ley 30/1992, sin que desde luego pueda amparar ni servir de soporte motivador aún tardío a aquella inactividad sanitario-prestacional ex-parte y ahora incluso ad quem impugnada.

En todo caso, la Sala reconoce expresamente la facultad de los médicos de actuar como contrapeso a las decisiones públicas de racionalización del gasto en ejercicio de su libertad de actuación como una garantía de la mejor protección de la salud de sus pacientes, lo que traslada la carga de la prueba a los poderes públicos: 
Reside en realidad ahí —en la omisión de valoración del juicio clínico de los propios facultativos oficiales de instancia-, donde radica el viciado núcleo fáctico de la inactividad prestacional-sanitaria ex-parte denunciada e, incluso, constitucionalmente infractora, sin que nunca se tomasen en consideración por aquel Ente institucional-autonómico las autorizadas opiniones científicas y médicas que reiteradamente abundaban en el criterio de proceder a suministrar a aquel paciente aquel principio médico antes referenciado como único medicamento eficaz, oficialmente autorizado y homologado, existente en el mercado farmacéutico, no solo a fin de conjurar aquellos potenciales riesgos vitales inherentes a dicha rara, grave y aún potencialmente letal patología sino, inclusive, en lo que se refiere a proporcionarle una mejor calidad de vida inclusive asimilable a la de cualquier persona sana [...] sin que en ningún caso sea de recibo la omisiva actuación de aquella Administración institucional-sanitaria y de aquella Comisión Autonómica Central de Farmacia y Terapéutica (CACFT), adscrita a la Consellería de Sanidad de la Xunta de Galicia que inspiró la misma sin valorar el acertado juicio clínico —en cuanto incluso a la postre científicamente corroborado según inclusive se reconoce de contrario por el Sr. Letrado de la Xunta de Galicia_- de sus propios profesionales de la Medicina y desde luego sin preocuparse siquiera por obtener juicio médico alternativo alguno hasta la fecha, en cuanto no fue nunca ni siquiera propuesta ni realizada prueba alguna y de contrario al efecto.

Normativamente, podemos encontrar tal mecanismo de contrapeso en la propia regulación de la prescripción y dispensación de medicamentos con cargo al sistema público; en concreto, en la reforma del art. 85 de la Ley 29/2006, de 26 de julio, de Garantías y Uso Racional de los Medicamentos y Productos Sanitarios, llevada a cabo por el Real Decreto Ley 9/2011, de 19 de agosto, de Medidas para la Mejora de la Calidad y Cohesión del Sistema Nacional de Salud, de Contribución a la Consolidación Fiscal y de Elevación del Importe Máximo de los Avales del Estado para 2011. Dicho precepto dispone que «La prescripción, indicación o autorización de dispensación de los medicamentos se realizará por principio activo, en la receta médica oficial u orden de dispensación, del Sistema Nacional de Salud» y "Asimismo, en los productos sanitarios para pacientes no hospitalizados que requieran para su dispensación en oficina de farmacia receta médica oficial u orden de dispensación, del Sistema Nacional de Salud, la prescripción, indicación o autorización de dispensación se realizará por denominación genérica por tipo de producto y por las características que lo definan, especificando su tamaño y contenido". Sin embargo, la norma añade in fine que "cuando las necesidades terapéuticas lo justifiquen [...] la prescripción, indicación o autorización de dispensación se podrá realizar identificando el medicamento o, en su caso, el producto sanitario por su denominación comercial». Obviamente, la necesidad terapéutica tendrá que establecerla un médico. 
En definitiva, el desarrollo de la prestación de la asistencia sanitaria en un marco público de protección de la salud delimita la autonomía de actuación del médico, aunque esta conserva aún un importante espacio de virtualidad. El médico mantiene en su virtud de su autonomía la facultad de actuar como contrapeso a determinadas decisiones de los poderes públicos que, pretendiendo salvaguardar el interés público, afecten singularmente a la salud concreta de un individuo.

\section{LA OBJECIÓN DE CONCIENCIA COMO UN PRESUPUESTO DE GARANTÍA DE LA LIBERTAD MÉDICA}

La conexión entre libertad de actuación médica y la objeción de conciencia es poco discutible. El propio Código Deontológico del Consejo General de Colegios Oficiales de Médicos señala en el art. 32, que encabeza la regulación de la objeción de conciencia, que el reconocimiento de la objeción de conciencia del médico es un presupuesto imprescindible para garantizar la libertad e independencia de su ejercicio profesional. Además, reconoce otra modalidad de objeción como es la objeción de ciencia, donde la divergencia que justifica la abstención del deber legal no posee una base moral, sino científica o clínica: «La objeción de ciencia tiene una protección deontológica al amparo del derecho a la libertad de método y prescripción, siendo diferente de la objeción de conciencia» (art. 33.2). Esta modalidad de objeción por criterios técnico-científicos tendría encaje en los dos mecanismos de contrapeso a los que nos hemos referido anteriormente, tanto desde la perspectiva que para los límites a la autonomía médica supone la autonomía del paciente que preside dicha relación (la facultad del médico de negarse a prestar la asistencia que se le exige por el paciente, siendo la misma contraria a la evidencia científica) como desde la que ofrece la inserción de la autonomía médica en el marco de una prestación de servicio público (la facultad del médico, en un contexto de limitación de recursos, de proponer un tratamiento que en el caso concreto supone una mejor protección de la vida o integridad del paciente).

Así pues, podemos considerar que la objeción de conciencia es una expresión, entre otras, de la autonomía del médico. En la relación clínica tradicional, la actuación en conciencia del profesional estaba basada en valores y deberes profesionales sobre los que existía unanimidad. En ella carecía de sentido hablar de objeción de conciencia. Es en la relación clínica moderna cuando surge la objeción de conciencia sanitaria, en un contexto de pluralidad axiológica, reconocimiento de la autonomía del paciente y creciente complejidad de la praxis clínica, donde los valores y deberes profesionales se definen de forma colectiva por los profesionales y por la sociedad (Seoane, 2014: 36). 
Además, ello es así no solo por los recientes cambios que han alterado la relación de poderes en la relación médico-paciente, sino, además, porque la objeción de conciencia constituye un debate muy moderno, prácticamente de nuestros días, que se desarrolla en las sociedades liberales y pluralistas (Gracia Guillén, 2009: 692).

El Comité de Bioética de España, en su Informe de 13 de octubre de 2011, considera que la objeción de conciencia exige la concurrencia de cuatro elementos: una norma jurídica de obligado cumplimiento, un dictado inequívoco de la conciencia individual opuesto al mandato jurídico, la ausencia en el ordenamiento jurídico de normas que permitan resolver el conflicto y la manifestación del propio sujeto del conflicto ${ }^{4}$.

En el ámbito de la medicina, la objeción de conciencia ostenta un valor cualificado que deriva de la conexión que la actividad que se desarrolla en dicho ámbito profesional tiene con valores tan trascendentales como la vida o la integridad física o psíquica de los individuos. Si antes hemos señalado, siguiendo la doctrina del TC sobre el consentimiento informado, que la autonomía del médico debe quedar sujeta a la del paciente en la medida en que esta es garantía de su vida e integridad, en similares términos podemos mantener que la objeción del médico ostenta una posición privilegiada al afectar a tales valores constitucionales esenciales. A este respecto, debemos recordar que el TC ha tratado de fijar una línea que permita delimitar aquellas objeciones que deben ser objeto de reconocimiento en nuestro sistema jurídico de aquellas otras que no, y esta línea se muestra clara cuando el argumento moral que se esgrime para permitir al objetor desligarse del deber legal conecta con la trascendencia del ser humano y con el propio concepto de la vida. Así, en la Sentencia 145/2015, el TC señala que

[...] sentadas las anteriores consideraciones, cumple afirmar que para la resolución del presente recurso resulta prioritario dilucidar si la doctrina enunciada en el fundamento jurídico 14 de la STC 53/1985 es también aplicable al caso que nos ocupa. Para despejar esa cuestión es preciso esclarecer, previamente, si los motivos invocados para no disponer de la "píldora del día después» guardan el suficiente paralelismo con los que justificaron el reconocimiento de la objeción de conciencia en el supuesto analizado por la Sentencia citada, al objeto de precisar si la admisión de dicha objeción, entendida como derivación del derecho fundamental consagrado en el art. 16.1 CE, resulta también extensible a un supuesto como el actual, en el que el demandante opone, frente a la obligación legal de dispensar el principio activo levonorgestrel $0,750 \mathrm{mg}$, sus convicciones sobre el derecho a la vida.

4 Puede accederse a dicho informe a través de la página web del Comité de Bioética de España, disponible en: www.comitedebioetica.es 
Una vez establecido el marco de la decisión, el TC concluye en los siguientes términos:

Con relación a esta cuestión, este Tribunal no desconoce la falta de unanimidad científica respecto a los posibles efectos abortivos de la denominada "píldora del día después». Sin perjuicio de ello, y a los meros fines de este procedimiento, la presencia en ese debate de posiciones científicas que avalan tal planteamiento nos lleva a partir en nuestro enjuiciamiento de la existencia de una duda razonable sobre la producción de dichos efectos, presupuesto este que, a su vez, dota al conflicto de conciencia alegado por el recurrente de suficiente consistencia y relevancia constitucional. En consecuencia, sin desconocer las diferencias de índole cuantitativa y cualitativa existentes entre la participación de los médicos en la interrupción voluntaria del embarazo y la dispensación, por parte de un farmacéutico, del medicamento anteriormente mencionado, cabe concluir que, dentro de los parámetros indicados, la base conflictual que late en ambos supuestos se anuda a una misma finalidad, toda vez que en este caso se plantea asimismo una colisión con la concepción que profesa el demandante sobre el derecho a la vida. Además, la actuación de este último, en su condición de expendedor autorizado de la referida sustancia, resulta particularmente relevante desde la perspectiva enunciada. En suma, pues, hemos de colegir que los aspectos determinantes del singular reconocimiento de la objeción de conciencia que fijamos en la STC 53/1985, FJ 14, también concurren, en los términos indicados, cuando la referida objeción se proyecta sobre el deber de dispensación de la denominada "píldora del día después» por parte de los farmacéuticos, en base a las consideraciones expuestas.

Los términos en los que se expresa el TC permiten concluir que dicha línea divisoria la marca fundamentalmente la conexión o no de la objeción de conciencia con un deber moral categórico incardinable en los derechos consagrados en el art. $15 \mathrm{CE}$. Con este argumento no pretendemos sostener que el TC niegue la virtualidad de otras objeciones basadas en diferentes deberes morales categóricos, pero sí que las expectativas por parte del individuo de ver reconocido legal o judicialmente el ejercicio de la objeción no serán tan evidentes como en los casos en los que el valor en discusión es la vida. Recuérdese que el propio TC ha aclarado en la misma sentencia que la objeción de conciencia no exige de regulación jurídica específica de cara a poder ser reconocida, ya que es una manifestación de la libertad ideológica y religiosa. Así, señala el TC que tal derecho existe y puede ser ejercido con independencia de que se haya dictado o no tal regulación. La objeción de conciencia forma parte del contenido del derecho fundamental a la libertad ideológica y religiosa reconocido en el art. 16.1 CE y, como ha indicado este TC en diversas ocasiones, la $\mathrm{CE}$ es directamente aplicable, especialmente en materia de derechos fundamentales. 
Con esta última decisión debe considerarse cerrado el debate doctrinal acerca de la necesidad o no de reconocimiento y desarrollo legislativo de la objeción de cara a su admisibilidad como una expresión legal de la conciencia personal. El TC parece optar por un línea intermedia entre dejar la objeción en manos del legislador (lo que no parece jurídicamente razonable si partimos de que la objeción es precisamente un mecanismo de contrapeso de la minoría en un sistema político que se rige por el principio de mayoría — sería un verdadero oxímoron considerar que dicho contrapeso necesita de la decisión de la mayoría para que la minoría pueda recurrir a él一) y reconocer un derecho general a la objeción de conciencia al amparo del art. $16 \mathrm{CE}$ (lo que tampoco parece razonable si pretendemos mantener la propia naturaleza del derecho como un sistema coercitivo y la preservación de una comunidad basada en el orden social que supone la decisión democráticamente adoptada por la mayoría).

El TC concluye que, si bien la objeción de conciencia no precisa de su reconocimiento ope legis, pudiendo admitirse su virtualidad pese a carecer de regulación expresa, ello no implica un derecho general que se deba objetar. Para que pueda admitirse la objeción es necesario que su fundamento conecte con valores o bienes de sustancial importancia como serían aquellos relacionados con la vida o, en palabras del propio TC, que la base conflictual que late se anuda a una colisión con la concepción que se profese sobre el derecho a la vida. Con tal afirmación no estamos, en todo caso, negando, como tampoco creemos que lo haga el TC, otras objeciones que pudieran traer causa de valores distintos del de la vida (véanse, entre otros, la objeción a ser miembro de un jurado o de una mesa electoral). Sin embargo, lo que es cierto es que en tales casos la exigencia de un previo reconocimiento por parte del legislador puede mostrarse menos plausible que en los casos a los que se refiere expresamente la citada Sentencia 145/2015 o, al menos, que su reconocimiento por un tribunal será más complejo a la vista del interés general que proteja el deber legal frente al que se pretende objetar. En materia de objeción de conciencia parece conveniente un tratamiento predominantemente jurisprudencial de los problemas, ya que son los jueces los que están en mejor situación para abordar el análisis individualizado que reclaman tales casos (Navarro Valls y Martínez Torrón, 2011: 33). Por ello, remitir la legalidad de la objeción a una decisión exclusiva del legislador no solo es contraria al propio fundamento de nuestra democracia constitucional, en la que la protección de los derechos de la minoría frente al principio de decisión mayoritaria está garantizada, sino que tampoco parece razonable, desde una perspectiva práctica, si atendemos a la propia diversidad de casos y situaciones concretas. La casuística que ofrece la decisión judicial parece un recurso adecuado, sin perjuicio de que pueda promoverse la regulación de determinados supuestos en pos de la seguridad 
jurídica (como hace, a título ilustrativo, la Ley Orgánica 2/2010, de 3 de marzo, de Salud Sexual y Reproductiva y de la Interrupción Voluntaria del Embarazo, en su art. 19.2). No puede confundirse la conveniencia de su regulación con una exigencia para cobrar eficacia jurídica.

Podría considerarse también que la posición por la que claramente ha optado ya el TC a partir de dicha sentencia concuerda, en gran medida, con la que ha venido manteniendo en nuestra doctrina científica, la cual conecta la objeción de conciencia con el principio de libertad de manera que cabría reconocer sin problema alguno, dentro de nuestras democracias liberales, un derecho general a la objeción de conciencia. La libertad es la regla y el deber jurídico, como límite a la libertad, es la excepción, por lo que considera que existe una presunción iuris tantum de legitimidad constitucional para quien actúa por motivos de conciencia. Ello no significa, sin embargo, que los deberes que operan como límites a la libertad de conciencia sean siempre ilegítimos o deban ser eliminados, pues tales deberes pueden proteger otros derechos ante los cuales la libertad del objetor haya de doblegarse. El objetor no tiene derecho a que el ordenamiento le tolere su comportamiento en cualquier supuesto, pero sí tiene derecho a que tal comportamiento sea considerado como el ejercicio de una libertad de conciencia en conflicto con los bienes o derechos protegidos por la norma objetada y que tal conflicto se resuelva de acuerdo con el test de proporcionalidad, como ocurre, añadimos nosotros, con cualquier conflicto constitucional entre un derecho individual y el interés general (Gascón Abellán, 2010: 149-154). En todo caso, ello debe matizarse porque de la sentencia se deduce que dicho reconocimiento general del derecho a la objeción de conciencia adquiere plenitud cuando la negativa a cumplir con el deber legal venga sustentada en un deber moral categórico singularmente trascendente como son aquellos que conectan directamente con el derecho a la vida. Fuera de dicho marco, el TC no rechaza la virtualidad de la objeción, aunque sí parece someterla a un escrutinio jurídico más exigente o que, al menos, no habrá de prevalecer siempre frente a la norma que protege el interés general o el de un tercero.

Debe tenerse en cuenta, también, que la objeción de conciencia no es una figura extraña a nuestra CE. Puede admitirse que constituya una excepción al deber general de cumplir el ordenamiento jurídico que, como no puede ser de otro modo, la propia CE instituye, pero no que sea algo impropio dentro del orden constitucional, cuando la propia CE reconoce expresamente la objeción de conciencia, aunque sea limitada al servicio militar obligatorio, en su art. $30.2 \mathrm{CE}$. Y tampoco lo ha sido para la propia jurisprudencia constitucional, ya que el TC ha mostrado siempre una especial sensibilidad a la objeción, guiado quizá por la influencia que la doctrina del Tribunal Constitucional Federal alemán ha ejercido sobre aquel, sobre todo, en lo que se refiere al 
concepto de dignidad humana que se desarrolla como reacción a los hechos ocurridos al final de la primera mitad del siglo xx. El epítome de ello no se encuentra tanto en la reciente Sentencia 145/2015, sino en la anterior Sentencia $154 / 2002$, en la que el TC resuelve el recurso de amparo presentado por unos padres testigos de Jehová que fueron condenados penalmente por no remover activamente el rechazo de su hijo menor de edad a recibir una transfusión de sangre. Ciertamente, el caso versó, principalmente, sobre la capacidad del menor a la hora de rechazar un tratamiento médico cuando tal posibilidad pone en riesgo su vida. Sin embargo, el TC también hubo de valorar, desde el punto de vista de la exigibilidad jurídica de una conducta diferente, la actitud de los padres en relación con la posición que mantuvo el hijo y, si en virtud de los deberes que se derivan de la patria potestad, debieron o no desarrollar una conducta más activa tendente a remover la negativa del hijo ${ }^{5}$. Como puede fácilmente comprobarse, se trata de un caso de objeción de conciencia por razón de las creencias religiosas a uno de los principales deberes jurídicos que recoge el ordenamiento jurídico, que no es otro que el deber de los padres de proteger a sus hijos, consagrado constitucionalmente en el art. 39.3 CE. En este caso, el TC admitió la validez de la objeción de conciencia, de manera que, atendiendo al deber legal frente al que se defendió la virtualidad de la objeción, es difícil sostener que su doctrina haya sido precisamente poco sensible a dicha figura, fuera de la excepción que supusieron las Sentencias 160 y 161/1987, a las que recurre frecuentemente parte de la doctrina tratando de sostener una posición constitucional restrictiva.

Pues bien, pudiendo considerar ya cerrado el debate acerca de la naturaleza jurídica y eficacia en nuestro sistema constitucional de la objeción de conciencia, y pudiendo también admitir un amplio margen a dicha institución en el ámbito de la salud, en la medida que las actuaciones que se desarrollan en dicho campo inciden habitualmente sobre la vida o integridad de las personas, surge un nuevo debate acerca de la posibilidad de admitirla en sentido positivo y no negativo como habitualmente ha sido aceptada por nuestra jurisprudencia; es decir, la posibilidad de que la objeción se exprese en forma de acción y no meramente de omisión como tradicionalmente venía ocurriendo. ¿Puede el objetor, no ya abstenerse por razones morales a llevar a

5 Según resulta del resumen de los hechos que se recoge en la propia sentencia, el personal sanitario, al ver que no podían convencer al menor, pidió a los acusados que trataran de convencer al niño, los cuales, aunque deseaban la curación de su hijo, no accedieron a ello, pues, como su hijo, consideraban que la Biblia, que Dios, no autorizaba la práctica de una transfusión de sangre, aunque estuviera en peligro la vida. 
cabo la conducta que le viene impuesta por el ordenamiento jurídico, sino, al contrario, llevar a cabo la que dicho ordenamiento le prohíbe?

Este debate no ha sido resuelto en la sentencia del TC sobre el Real Decreto Ley 16/2012, dado que no ha sido tal discusión objeto del recurso de inconstitucionalidad planteado frente a aquella norma, y ello pese a que tal nueva modalidad de objeción surge precisamente con ocasión de la respuesta de varios colectivos profesionales y sociales a la limitación a la asistencia sanitaria a los inmigrantes sin papeles que se recogía en la norma ${ }^{6}$. En todo caso, también es cierto que el impacto efectivo del conflicto quedó muy diluido, dado que varias comunidades autónomas aprobaron diferentes medidas legales para dejar sin efecto en su ámbito de competencia sanitaria tal limitación, lo que hizo innecesario que los profesionales tuvieran que recurrir en expresión de su libertad de conciencia a dicha objeción positiva.

El problema que plantea esta nueva modalidad de objeción deberá ser abordado desde una doble perspectiva, una más general en la que habrá que preguntarse si cabe admitir la objeción como una expresión activa o una objeción de conciencia positiva y otra más específica en la que deberemos plantearnos si, admitiéndose con carácter general, puede aceptarse en el caso concreto que se ha planteado al amparo de la nueva situación planteada por el citado Real Decreto Ley 16/2012.

En lo que a la primera cuestión se refiere, no vemos problema conceptual alguno en aceptar la objeción de conciencia positiva, ya que, si es expresión de libertad, ha de presumirse prima facie su legitimidad sin perjuicio de que ello no implique que no pueda verse limitada por otros derechos o intereses

6 El Real Decreto Ley modifica el tenor del art. 3 Ley 16/2003, de 28 de mayo, de Cohesión y Calidad del Sistema Nacional de Salud, de manera que los emigrantes sin papeles quedan fuera de los supuestos que dan lugar a adquirir la condición de asegurado, estableciendo el apdo. 3: «En aquellos casos en que no se cumpla ninguno de los supuestos anteriormente establecidos, las personas de nacionalidad española o de algún Estado miembro de la Unión Europea, del Espacio Económico Europeo o de Suiza que residan en España y los extranjeros titulares de una autorización para residir en territorio español, podrán ostentar la condición de asegurado siempre que acrediten que no superan el límite de ingresos determinado reglamentariamente». Ello acaba por completarse con lo dispuesto en el siguiente apdo. 5 que supone una mención tácita a los emigrantes sin papeles: «Aquellas personas que no tengan la condición de asegurado o de beneficiario del mismo podrán obtener la prestación de asistencia sanitaria mediante el pago de la correspondiente contraprestación o cuota derivada de la suscripción de un convenio especial». Por tanto, los emigrantes sin papeles pierden la condición de asegurados y pueden, a partir de ahora, acceder a las prestaciones sanitarias a cambio del pago de una contraprestación o cuota. 
dignos también de protección. No existen argumentos para otorgar prioridad moral ni para proteger selectivamente las objeciones negativas, aunque el contexto social y político norteamericano muestra una tendencia favorable a garantizar estas, identificadas con posiciones socialmente conservadoras (social conservatives), prestando menor atención a las objeciones positivas, vinculadas a posiciones socialmente liberales o progresistas (social liberals). No obstante, en la medida en que ambas pretenden garantizar la integridad moral del profesional asistencial, que es la razón principal que justifica el reconocimiento de la objeción de conciencia, ambas son igualmente merecedoras de protección (Seoane, 2014: 38). Así pues, desde una perspectiva general, no parece que exista problema alguno en reconocer cierto espacio de virtualidad a la objeción de conciencia positiva con carácter general y al margen del conflicto del que nos vamos a ocupar de inmediato.

En lo que se refiere en concreto ya al conflicto planteado al amparo del Real Decreto Ley 16/2012, nos encontramos ante un supuesto muy específico de objeción de conciencia positiva, ya que esta incide sobre una prohibición legal que deriva de las facultades que nuestro ordenamiento constitucional atribuye en su art. 53.3 a los poderes públicos para configurar el contenido efectivo de los derechos sociales. La objeción de conciencia positiva destaca, como ya hemos apuntado antes, por la pretensión de eximirse de la norma, llevando a cabo, por motivos de conciencia, una conducta positiva prohibida. Sin embargo, en este caso, lo que se plantea es desatender una decisión adoptada por los poderes públicos en ejercicio de la función constitucional de configurar el Estado prestacional y, además, haciendo uso de bienes y medios de titularidad pública, de prestaciones públicas.

Sobre la virtualidad de esta modalidad específica de objeción positiva se han pronunciado en diferente sentido un Servicio de Salud y la doctrina. En efecto, en contra de esta modalidad de objeción positiva se pronunció hace un tiempo el Servicio de Asesoramiento Jurídico de la Consejería de Sanidad y Servicios Sociales de Cantabria con ocasión del debate planteado en dicha comunidad acerca de la limitación de la asistencia sanitaria a los inmigrantes sin papeles. En su Informe de 7 de agosto de 2012 se pronuncia en contra de tal posibilidad por tres motivos que cita de manera sucesiva.

En primer lugar, considera que, al amparo de la doctrina del TC (con especial mención de la contenida en la ya citada STC 161/1987), la objeción de conciencia no constituye un derecho fundamental de alcance general, sino que se trata de un derecho de configuración legal cuyo ejercicio exige un reconocimiento expreso. Esta doctrina, como hemos visto, se ha visto ya superada por la más reciente contenida en la Sentencia 145/2015 que sí reconoce el alcance general de la objeción lo que, obviamente, no significa que deba atenderse cualquier pretensión de abstenerse por motivos de conciencia del 
cumplimiento de un deber legal, sino que para acudir a esta no es necesario que haya previsión normativa expresa al respecto.

En segundo lugar, porque el personal sanitario al servicio del sistema sanitario público, se encuentra en una situación de sujeción especial con ciertas implicaciones que se traducen en la vinculación al principio constitucional de jerarquía y en el sometimiento a la ley y al derecho (art. 103.1 CE); un argumento que consideramos que goza de escasa virtualidad en relación con el debate sobre la objeción de conciencia porque implicaría, en sí mismo, que la objeción carece de eficacia en las relaciones de sujeción especial, lo que en modo alguno ha sido reconocido en nuestro ordenamiento jurídico y menos por el TC.

Por último, porque el supuesto invocado en el presente supuesto no constituye una actitud omisiva, consustancial a la configuración de la objeción de conciencia, sino, por el contrario, en la adopción de un comportamiento activo que, en ningún caso, puede encontrar cobertura en el derecho a la objeción de conciencia. Como puede comprobarse, el rechazo a la objeción positiva se basa más en una concepción histórica de la figura que en su propio fundamento, más aún, cuando estamos ante un fenómeno cambiante y en permanente evolución, fruto de una sociedad más plural y compleja. El elemento que singulariza el caso que nos ocupa, la condición de habilitación que concurre en la conducta activa del objetor, informa, a nuestro parecer, en contra de admitir la objeción en este caso concreto. A este respecto, debe recordarse que nuestro ordenamiento jurídico distingue entre habilitaciones para actuar y abstenciones para no hacerlo al margen de la norma, de manera que equiparar jurídicamente ambos fenómenos parece, al menos, complejo con carácter general. La propia distinción entre la eficacia jurídica de las libertades tradicionales y los derechos sociales parte precisamente de los principales deberes que para el Estado suponen ambas, las primeras de abstención y las segundas de prestación. Véase, por ejemplo, el derecho a la protección de la salud que, en su condición de principio rector con eficacia inmediata limitada, deriva de la obligación de dar que para los poderes públicos supone. Constituye un derecho con alto contenido económico, exigiendo su satisfacción no una mera abstención por parte de los poderes públicos, como ocurre con las clásicas libertades públicas que integran los denominados derechos de primera generación, sino la inversión de importantes partidas económicas para cumplir con su obligación de dar. Ha de recordarse que los derechos sociales son derechos complejos y que, como tales, exigirán una respuesta desde la estructura orgánica de la CE distinta de la que desde el mismo constitucionalismo liberal se proponía para los derechos fundamentales y libertades públicas (Cascajo Castro, 2012: 29-30). Ello ha sido reiterado por el TC en su Sentencia de 21 de julio de 2016 sobre la constitucionalidad del Real Decreto Ley 16/2012. Así, el TC señala a este 
respecto que «el legislador, de acuerdo con el inherente componente de flexibilidad que caracteriza el marco constitucional, dispone de un amplio margen de configuración con relación al art. $43 \mathrm{CE}$, en tanto que precepto incluido en el Capítulo III del Título I de la Constitución».

Cierto es que la objeción constituye una expresión de la libertad de conciencia que, como tal, pertenece a los derechos de primera generación y no encuentra las limitaciones en cuanto a su eficacia que ofrecen los derechos sociales, pero ello no obsta para que, a través del argumento que hemos desarrollado, no se aprecie cómo la habilitación no se equipara a la mera abstención en nuestro ordenamiento jurídico. En el propio derecho administrativo puede apreciarse la misma distinción entre habilitación y mera tolerancia o, en similares términos, entre concesión y autorización. La respuesta jurídica que recibe la conducta del administrado consistente en desarrollar una acción u omisión dentro de un ámbito que originariamente correspondería a su espacio de libertad —o, lo que es lo mismo, a su posibilidad de actuación en la esfera personal, pero que, por razones de protección del interés público o de intereses de terceros, la norma administrativa ha limitado- es bien distinta a aquella otra que supone ejercer su libertad en un ámbito que originariamente no tiene reconocido, como podría ser, por ejemplo, el uso del dominio público. En el primer caso, hablamos, como venimos diciendo, de una mera tolerancia por parte de la Administración o, en su caso, de la remoción de los límites a un estado inicial de libertad (autorización), mientras que en el segundo hablaríamos ya de una verdadera habilitación (concesión). La diferencia radica, pues, como plantea la doctrina administrativa, en la titularidad de base existente y en el carácter declarativo o constitutivo respecto de la esfera del administrado. En la objeción de conciencia positiva que es objeto de nuestro debate no se solicita ni el levantamiento de una prohibición general de la actividad en cuestión, expandiéndose así el ámbito genérico de la libertad individual, ni la remoción de los límites impuestos al ejercicio de un derecho subjetivo preexistente (De la Cuétara Martínez, 1983: 258-259), sino la concesión de la facultad previa inexistente que es la de ofrecer una prestación pública. Frente a ello no puede argumentarse que previamente el facultativo sí podía ofrecer la prestación al inmigrante sin papeles, con anterioridad al cambio que en nuestro ordenamiento opera el citado Real Decreto Ley 16/2012, so pena de incurrir en un error de concepto acerca de la naturaleza de las prestaciones y servicios públicos. El facultativo personal público de la Administración no tiene un espacio previo y originario de libertad que le habilite para prestar los servicios que estime más adecuados para el paciente, sino un espacio de actuación que le viene delimitado, no limitado, por el catálogo público de prestaciones. Por ello, el mero elemento fáctico de que anteriormente la norma lo 
habilitara para ofrecer gratuitamente dicha prestación no altera dicho carácter delimitado de su libertad, no limitado.

No puede equipararse $-\mathrm{y}$, por ende, recibir la misma respuesta jurídica la conducta del médico que pretende que se le exima del deber legal de ofrecer una prestación cuando ello afecta a su conciencia- lo que se corresponde con un espacio previo de libertad que se ha visto limitado por norma con aquel otro profesional que pretende ofrecer una prestación cuando tiene prohibido por norma hacerlo, aún cuando ambas se fundamenten en la misma libertad de conciencia, y ello, sin olvidar que el segundo caso estamos hablando de habilitar al sujeto para disponer libremente contra legem de un bien público, concederle una autorización de uso privativo de dicho bien en satisfacción de su libertad de conciencia.

Sirva como ejemplo de lo que venimos planteando el propio régimen jurídico del silencio administrativo, por el que la concesión de una habilitación de actuar se sujeta al silencio negativo, mientras que la mera tolerancia se somete a las reglas más favorables para el administrado del silencio positivo (véanse los arts. 24 y 25 Ley 39/2015, de 1 de octubre, del Procedimiento Administrativo Común de las Administraciones Públicas: entre otros, aquellos cuya estimación tuviera como consecuencia que se transfirieran al solicitante o a terceros facultades relativas al dominio público o al servicio público, impliquen el ejercicio de actividades que puedan dañar el medio ambiente o de los que pudiera derivarse el reconocimiento o, en su caso, la constitución de derechos u otras situaciones jurídicas favorables). Tal diferente régimen jurídico del silencio responde, como no puede ser de otra manera, a la diferente posición de poder que ocupan los poderes públicos en el ámbito de la habilitación y en el de la mera tolerancia.

Así pues, y aunque, como planteamiento general, es difícil esgrimir un argumento que permita negar la virtualidad de la objeción positiva en cuanto expresión de libertad, mostrándose harto complejo no poder trasladar los mismos argumentos que sustentan la objeción negativa a la positiva porque ambas son expresión de la misma libertad, la habilitación jurídica para actuar que su reconocimiento parece exigir un tratamiento jurídico diferente del que se otorga a la mera abstención, más aún, cuando ello incida en el propio poder configurador de los derechos sociales que le corresponde a los poderes públicos. La habilitación frente a la mera omisión queda sujeta a unos requisitos específicos menos flexibles y permisivos, ya que no se trata ya de respetar el ámbito de libertad que corresponde al ciudadano frente a la conducta que le impone el deber consagrado normativamente, sino de habilitarlo para hacer algo que va más allá de su esfera propia de libertad, permitirle actuar en un ámbito en el que no se le reconoce naturalmente tal libertad. 
Pero es que, además, puede apreciarse otra diferencia sustancial entre la objeción positiva y negativa, y esta es la de la diferente naturaleza del conflicto que se plantea en ambos casos. Si atendemos al conflicto específico con ocasión del cual estamos desarrollando nuestro debate, pueden apreciarse dos elementos que lo singularizan frente a las expresiones negativas de libertad de conciencia en el ámbito sanitario: por un lado, como ya hemos explicado, el carácter habilitante que transforma una obligación de no hacer en una autorización de dar, por el otro, el hecho de que el conflicto no se plantea ya entre dos derechos que colisionan, sino entre un derecho y el interés general.

El problema radica, en este caso concreto, en que el conflicto no enfrenta la libertad del objetor con el derecho del sujeto titular de la prestación que aquel, en reivindicación de un categórico moral, se abstiene de satisfacer (como ocurriría, en términos meramente didácticos, en el caso de la interrupción voluntaria del embarazo o de la píldora abortiva), sino a dicha libertad con el interés general que pretende protegerse a través de la medida adoptada por el poder público en ejercicio de su facultad de configurar el derecho a la salud en garantía de la sostenibilidad del sistema sanitario. Si se admite la objeción del facultativo que se niega por razones de conciencia a cumplir la prohibición de ofrecer la prestación, se estaría permitiendo no limitar el derecho a la prestación, sino su sacrificio. Véase que la regulación de la objeción no permite un sacrificio del derecho a la prestación del que exige acceder a esta, sino una mera limitación, mientras que, en el caso que nos estamos planteando, admitir que los médicos pueden objetar positivamente de la norma supone a la postre un sacrificio, no una mera limitación, del interés general que se pretende satisfacer a través de ella, más aún, cuando dicho interés no es otro que el de la sostenibilidad del sistema público de salud consagrado en el art. $43 \mathrm{CE}$.

Por otro lado, debemos recordar que el Real Decreto Ley 16/2012 no excluye a los inmigrantes sin papeles del derecho a la asistencia sanitaria, sino que lo limita sujetándolo a unos requisitos, pero garantizando, en todo caso, un mínimo esencial, un mínimo garantizado que se refiere, precisamente, a aquellos casos en los que el derecho a la vida y a la integridad puede verse más comprometido o que vienen referidos a colectivos especialmente vulnerables (véase asistencia en situaciones de urgencia, asistencia a embarazadas y menores de edad). Sin embargo, excluir la objeción positiva sobre la base de este argumento de respeto del mínimo esencial aboca a la postre a un debate más ideológico que jurídico de manera que consideramos que la principal objeción a la objeción positiva, con perdón por la redundancia, se basa más en la naturaleza del conflicto que se plantea en el caso concreto, un conflicto entre un derecho individual y el interés general que en las propias circunstancias que 
concurren respecto de la limitación del derecho a la asistencia sanitaria de los inmigrantes sin papeles.

Pero es que, además, puede también sostenerse desde la teoría de los derechos sociales y de su plasmación constitucional como meros principios rectores que, si los poderes públicos tienen una mayor potestad de configuración de estos frente a las libertades tradicionales, será lógico admitir que la operatividad de la objeción de conciencia frente a tal mayor poder configurador será necesariamente inferior. Si las facultades de control que sobre la decisión pública que afecte a los principios rectores les corresponde a los tribunales es inferior a la que se les atribuye respecto de los derechos y libertades, lo que la doctrina ha denominado de manera muy ilustrativa, "posición de creatividad inferior de los Tribunales» (Cossío Díaz, 1989: 268-269), no puede admitirse que los ciudadanos también sujetos al ordenamiento dispongan de una amplia facultad de desvincularse de la norma cuando ello incide en las funciones de ordenación de los recursos económicos.

Como nos recuerda el TC en la Sentencia de 21 de julio de 2016, el derecho a la salud

[...] se configura y concreta de acuerdo con lo que dispone la ley, que debe regular las distintas condiciones y términos en los que se accede a las prestaciones y servicios sanitarios. Es posible, en términos constitucionales, la falta de identidad entre el derecho al acceso universal al sistema de salud pública de ese «todos» del art. $43 \mathrm{CE}$, con que ese acceso a la sanidad pública incluya beneficiarse de un concreto régimen de prestaciones sanitarias gratuitas o bonificadas con cargo a fondos públicos [...] Será la legislación la que en cada momento determine el alcance y la graduación de esa gratuidad, así como de las bonificaciones económicas en las prestaciones sanitarias de acuerdo con las exigencias derivadas de las circunstancias cambiantes, respetando los límites constitucionales.

Sin olvidar, además que «la sostenibilidad del sistema sanitario público impone a los poderes públicos la necesidad de adoptar medidas de racionalización del gasto sanitario, necesarias en una situación caracterizada por una exigente reducción del gasto público, de manera que las Administraciones públicas competentes tienen la obligación de distribuir equitativamente los recursos públicos disponibles y favorecer un uso racional de este Sistema» (ATC 96/2011), es decir, lo que se ha denominado «reserva económica de lo posible» (Carmona Cuenca, 2000. 159).

En definitiva, consideramos que, si bien, desde una perspectiva general, puede admitirse la virtualidad en determinados casos de la objeción de conciencia positiva, en el caso que estamos abordando, el de la abstención a cumplir una prohibición legal, prestando la asistencia sanitaria que el sistema público de 
salud no permite, no parece admisible por los diferentes argumentos que hemos expuesto - entre los que destacan tanto la distinción que el propio sistema jurídico hace entre inmunidades y habilitaciones como el de la diferente naturaleza del conflicto que subyace en este caso y, además, el del diferente poder de configuración que los poderes públicos tienen en materia del derecho a la salud como principio rector, lo que necesariamente informa a favor de restringir la conducta que pretenda oponerse a dicho poder.

Otra cuestión distinta será admitir sobre la base del estado de necesidad o de la inexigibilidad de otra conducta que, en casos muy específicos, el incumplimiento de la prohibición no ha de conllevar consecuencia jurídica alguna para el objetor o, al menos, que dichas consecuencias se vean especialmente atenuadas o minoradas, ya que, como hemos mantenido antes, el médico ostenta, en virtud de su libertad de actuación, una facultad de contrapeso a determinadas decisiones generales que, en casos concretos, pueden mostrarse claramente contrarias a la salud del paciente. Así pues, admitir que el profesional ofrezca gratuitamente el servicio que se encuentra limitado por norma es posible en casos específicos, pero no con carácter general como expresión de la objeción de conciencia positiva. Atender a un inmigrante sin papeles en contravención de la norma en un caso específico no puede equipararse, jurídicamente, a negarse a cumplir la prohibición con carácter general por razones de conciencia.

\section{CONCLUSIONES}

La libertad de actuación médica se ha visto ciertamente sometida a importantes cambios que derivan de dos importantes fenómenos: la inserción de la relación médico-paciente en el marco de un sistema público prestacional - lo que exige adoptar medidas que, garantizando la sostenibilidad del sistema, limitan la capacidad de decisión del profesional—y la aparición del principio de autonomía del paciente, que le exige a aquel respetar la voluntad de este. Sin embargo, como hemos mantenido en nuestro trabajo, creemos que dicha libertad mantiene su vigencia pese a los cambios operados en la citada relación médico-paciente. Tal vigencia se expresa en un doble sentido: por lo que se refiere a los límites que pudieran afectar a la autonomía de decisión del médico derivados de la exigencia de la sostenibilidad el sistema público de protección de la salud, el médico mantiene una facultad de contrapeso que le permite en casos concretos apartarse del criterio general establecido, siempre que ello venga singularmente exigido por el mejor interés del paciente y así, por ejemplo, poder prescribir un medicamento o una prueba diagnóstica más cara de la establecida, con la debida carga de informar de los motivos de dicha decisión médica. Este deber de informar no supone una limitación irrazona- 
ble de su libertad, siempre que la valoración, obviamente, se realice con criterios terapéuticos, no económicos, ni administrativos. Se trata de una medida que permite controlar el gasto sin perjuicio ni del usuario, en la medida en que, de ser aprobado, obtendrá la financiación pública de lo prescrita, ni del profesional, que podrá actuar conforme a su leal saber y entender.

Debe recordarse que la libertad médica es instrumental en la medida en que es garante de la calidad de la asistencia a los pacientes y, en cuanto tal, incide directamente sobre su derecho a la vida e integridad física y psíquica. Dicha característica es la que creemos que debe permitir cierto poder de resistencia al médico frente a la decisión del poder público sanitario cuando sus decisiones puedan incidir directamente en la salud o integridad de los pacientes.

Por lo que se refiere a la autonomía de voluntad del paciente que necesariamente condiciona la decisión del médico o, mejor dicho, su actuación, creemos que esta conserva, al amparo de tal libertad, el derecho de no llevar a cabo acciones positivas contrarias a la evidencia científica o que el profesional considere menos idóneas o innecesarias según la lex artis ad hoc. El paciente no está legitimado para obligar al médico a actuar en contra de la lex artis ad hoc. La autonomía habilita al paciente a negarse a un determinado tratamiento aún con riesgo de su vida, pero no lo faculta para exigir la aplicación de un tratamiento contrario a dicha evidencia científica. Admitir lo contrario implica exigir al médico que infrinja uno de los principales deberes éticos (o, incluso, podríamos decir el principal deber ético) que informa su conducta: el de primum non nocere que la bioética contemporánea expresa como un principio de no maleficencia.

Por último, y por lo que se refiere a la objeción de conciencia como expresión de la libertad de actuación del médico, el reciente debate planteado en relación con la posibilidad de que los facultativos puedan abstenerse de cumplir con la prohibición de prestar asistencia sanitaria gratuita a los inmigrantes sin papeles, fuera de los casos previstos por el Real Decreto Ley 16/20012, en garantía del contenido esencial del derecho a la protección de la salud (urgencias, asistencia a los menores y a las embarazadas), creemos que, si bien no hay problema alguna en que puedan admitirse algunas formas de objeción positiva, no por ello puede admitirse tal expresión concreta de la libertad de conciencia. Y ello por tres motivos fundamentales: por la distinción que el propio sistema jurídico establece entre inmunidades y habilitaciones; por la diferente naturaleza del conflicto que subyace en este caso, que enfrenta la conciencia del facultativo con el interés general; $y$, por último, atendiendo al diferente poder de configuración que los poderes públicos tienen en materia del derecho a la salud como principio rector, lo que necesariamente informa a favor de restringir la conducta que pretenda oponerse a dicho poder. 


\section{Bibliografía}

Alemany, M. (2011). El paternalismo médico. En M. Gascón Abellán, M. C. González Carrasco y J. Cantero Martínez (coords.). Derecho sanitario y bioética. Cuestiones actuales (pp. 745-788). Valencia: Tirant lo Blanch.

Armenteros Chaparro, J. C. (1997). Objeción de conciencia a los tratamientos médicos: la cuestión de la patria potestad. Madrid: Colex.

Barrero Ortega, A. (2002). Sobre la libertad religiosa [tesis doctoral]. Sevilla: Universidad de Sevilla.

Barrios Flores, L. F. (2006). Los aspectos legales de la transfusión. Madrid: Ferrer Farma Hospital.

Beato Espejo, M. (1994). El derecho a la prestación sanitaria: libertad de prescripción y dispensación. Derecho y Salud, 2, 59-80.

Beltrán Aguirre, J. L. (2005). La objeción de conciencia de los profesionales sanitarios. Derecho y Salud, 13, 63-72.

— (2016). Autonomía del paciente: límites derivados de la cartera de servicios, de la organización y funcionamiento de los centros sanitarios y de otros derechos y bienes enfrentados. En M. L. Arcos Vieira (dir.). Autonomía del paciente e intereses de terceros: limites (pp. 73-130). Cizur Menor: Thomson Reuters Aranzadi.

Carmona Cuenca, E. (2000). El Estado social de derecho en la Constitución. Madrid: Consejo Económico y Social.

Cascajo Castro, J. L. (coord.) (2012). Derechos sociales y principios rectores. En Actas del IX Congreso de la Asociación de Constitucionalistas de España (pp. 17-44). Valencia: Tirant lo Blanch.

Cossio Díaz, J. R. (1989). Estado social y derechos de prestación. Madrid: Centro de Estudios Constitucionales.

De la Cuétara Martínez, J. M. (1983). La actividad de la Administración. Lecciones de Derecho Administrativo. Madrid: Tecnos.

De los Reyes López, M. (2001). Relaciones entre profesionales sanitarios. Bioética para Clínicos. Medicina Clínica, 117, 339-350. Disponible en: https://doi.org/10.1016/ S0025-7753(01)72107-0

— (2007). Marco ético de la Sociedad Española de Cardiología. Madrid: Sociedad Española de Cardiología.

De Miguel Beriain, I. (2009). La objeción de conciencia del farmacéutico: una mirada crítica. Revista de Derecho de la UNED, 6, 173-198.

Gascón Abellán, M. (2010). Objeción de conciencia sanitaria. En B. Mendoza Buergo (ed.). Autonomía personal y decisiones médicas. Cuestiones éticas y jurídicas (pp. 143162). Cizur Menor: Thomson Reuters-Civitas.

Gómez Abeja, L. (2016). Las objeciones de conciencia. Madrid: Centro de Estudios Políticos y Constitucionales.

Gracia Guillén, D. (2009). Ética en la objeción de conciencia. Anales de la Real Academia Nacional de Medicina, 126, 691-712. 
Martorell, M. V. y Sánchez-Urrutia, A. (2005). Documento sobre el rechazo a las transfusiones de sangre por parte de los testigos de Jehová. Barcelona: Observatori de Bioética i Pret.

Navarro-Valls, R. y Martínez-Torrón, J. (2011). Conflictos entre conciencia y Ley. Las objeciones de conciencia. Madrid: Iustel.

Seoane, J. A. (2014). Objeción de conciencia positiva. Revista de Bioética y Derecho, 32, 34-45. Disponible en: https://doi.org/10.4321/S1886-58872014000300004

— (2016). ¿Objeción de conciencia sanitaria positiva? En J. A. Santos, M. Albert y C. Hermida (eds.). Bioética y nuevos derechos (pp. 295-310). Granada: Comares.

Tajadura Tejada, J. (2016). El respeto a la Ley y la objeción de conciencia. Claves de Razón Práctica, 244, 68-77.

Villar Rojas, F. J. (1997). Medidas de racionalización; libertad de prescripción. Derecho y Salud, 5 (2), 105-116. 